\title{
Universiteit
}

Leiden

The Netherlands

\section{Decomposing employment trends of disabled workers}

Koning, P.W.C.; Vethaak, H.T.

\section{Citation}

Koning, P. W. C., \& Vethaak, H. T. (2021). Decomposing employment trends of disabled workers. The B.e. Journal Of Economic Analysis \& Policy, 21(4), 1217-1255. doi:10.1515/bejeap-2021-0010

Version: Publisher's Version

License: $\quad$ Creative Commons CC BY 4.0 license

Downloaded from: $\quad$ https://hdl.handle.net/1887/3242848

Note: To cite this publication please use the final published version (if applicable). 


\title{
Research Article
}

\section{Pierre Koning* and Heike Vethaak Decomposing Employment Trends of Disabled Workers}

\begin{abstract}
This paper estimates Age-Period-Cohort models on employment rates of Dutch Disability Insurance (DI) applicants. We find that the substantial decrease in employment between 1999 and 2013 is explained by year-of-application cohort effects and that period effects are negligible. In turn, application cohort effects partly stem from increasing shares of applicants without permanent contracts. Changes in application cohort effects are largely confined to the years following two DI reforms that increased self-screening among workers. We next analyze changes in employment rates of awarded and rejected applicants and follow a Difference-in-Differences approach. Assuming common compositional cohort effects, we infer negligible effects of changes in benefit conditions.
\end{abstract}

Keywords: employment, disability insurance, APC models, self-screening JEL codes: H75, J21, C23

\section{Introduction}

Over the last decades, many OECD countries have shown declining employment rates of disabled individuals (OECD 2010). For the US, there is strong evidence that

\footnotetext{
* Corresponding author: Pierre Koning, Vrije Universiteit Amsterdam, Universiteit Leiden, TI and IZA, Amsterdam, The Netherlands, E-mail: p.w.c.koning@vu.nl. https://orcid.org/00000002-8808-9497

Heike Vethaak, Universiteit Leiden, Leiden, The Netherlands, E-mail: h.t.vethaak@law.leidenuniv.nl. https://orcid.org/0000-0001-7579-1132
}

¿open Access. @2021 Pierre Koning and Heike Vethaak, published by De Gruyter. (@) BY This work is licensed under the Creative Commons Attribution 4.0 International License. 
the Social Security Disability Insurance (SSDI) program has become a more attractive scheme for low-skilled workers (Autor and Duggan 2003; Bound, Burkhauser, and Nichols 2003; Bound, Lindner, and Waidmann 2014; Maestas 2019; Von Wachter, Song, and Manchester 2011). Since the mid-eighties, the expansion of the SSDI program coincided with higher fractions of applicants with weak labor market positions for whom the receipt of benefits has discouraged them from working. This means that overall decline in employment among SSDI recipients can be attributed both to changes in the composition of applicants - with vulnerable labor market positions - and a lack of work incentives for those awarded benefits. This raises two fundamental questions that are inherent with the design of Disability Insurance (DI) schemes. The first is on the targeting of benefits: who should be eligible to DI? In this respect, DI benefits can either be restricted to workers with severe disabilities or expanded to vulnerable workers with mild impairments that cannot engage in substantial gainful activities. The second question concerns the design of work incentives: how can benefit recipients be encouraged to exploit their remaining earnings capacity? For the overall assessment of DI reforms, it thus is of key importance to both address targeting effects - i.e. compositional changes - and incentive effects.

This paper provides such a broad assessment of the employment trends of DI applicants in the Netherlands, a country that also experienced strong decreases in the labor force attachment of claimants. In the Netherlands, drastic reforms have been implemented to curb the inflow into DI as well as increase work incentives for disabled workers. On the one hand, increases in screening stringency and eligibility thresholds changed the composition of new applicant cohorts. This increased the severity of new claims and decreased their employment rates (De Jong, Lindeboom, and Van der Klaauw 2011; Godard, Koning, and Lindeboom 2019). ${ }^{1}$ On the other hand, the new disability law that started in 2006 increased work incentives for new DI recipients with residual earnings capacities. Koning and van Sonsbeek (2017) show that this increased the individual employment rates of awarded applicants. Taken together, the reforms have both changed the targeting efficiency as well as the work incentives of the DI scheme.

To incorporate both selection and incentive effects in the assessment of employment trends of disabled workers, this paper is the first to estimate Age-Period-Cohort (APC) models on administrative applicant data. We focus on DI applicant cohorts between 1999 and 2013 which are followed up to 2016. In the context of our model, 'age' corresponds to the elapsed duration since application,

1 Contributions of Campolieti (2006) for Canada, Deshpande and Li (2019) for the US, Markussen, Røed, and Schreiner (2018) for Norway and Liebert (2019) for Switzerland suggest that increased scrutiny and increased application costs have the potential to substantially lower DI inflow rates. 
period effects capture business cycle and other calendar time effects, and cohort effects resemble changes in employment rates that are specific to annual DI application cohorts. Using a Deaton-Paxson (DP) specification, we first disentangle application cohort effects from period and age effects. These application cohort effects represent the joint effect of: (i) compositional changes induced by secular cohort-specific time trends in the demand for and health conditions of the insured population of workers with disabilities; (ii) compositional changes induced by disability reforms that affected self-screening before application; and (iii) individual changes in the employment rate of awarded applicants - or: 'incentive effects' - induced by cohort-specific changes in benefit conditions. With reforms in the Netherlands that affected new applicant cohorts only, both changes in the targeting and in incentive effects are embodied in year-of-application cohort effects.

Our second aim is to provide a further decomposition of the application cohort effects into changes stemming from compositional changes ('targeting') and changes in the individual's employment probability stemming from DI reforms ('incentive effects'). In the spirit of Bound (1989), we follow a Difference-inDifferences (DiD) approach with awarded and rejected DI applicants as treatment and control groups. ${ }^{2}$ Assuming that compositional effects - both induced by reforms and gradual changes in the labor market - affected treatment and control cohort groups equally, the DiD estimates of the reforms indicate changes in the individual employment probability of awarded applicants. Stated differently, we assume that changes in employment probabilities caused by compositional differences across application cohorts are equal in magnitude for awarded and rejected applicants and are captured by an additive application cohort effect common to both awarded and rejected applicants. The residual change in employment rates for awarded applicants can then be characterized as the 'incentive' effects of the reforms on awarded applicants.

Our main research findings can be summarized as follows. First, application cohort effects of DI applicants are the main contributor to their observed decline in employment, amounting to about 30 percentage points in total. Contrasting to this, the effect of calendar time effects is negligible, suggesting that both business cycle effects or secular time trends that affected all application cohorts equally

2 To estimate the discouraging impact of SSDI benefits, Bound (1989), Chen and Van der Klaauw (2008), Von Wachter, Song, and Manchester (2011), Maestas, Mullen, and Strand (2013), and French and Song (2014) compare accepted and denied SSDI applicants. Following the seminal article by Bound (1989), the resulting estimates form an upper bound of the employment rates of awarded applicants, since rejected applicants are considered to have more labor market attachment than accepted applicants. 
were not important. Second, changes in application cohort effects are largely in tandem with the disability reforms of 2003 and 2006; it is only for the years after the 2006 reform that we observe a gradual and substantial further decline in cohort effects. Third, our DiD-analysis provides limited evidence for employment rates to respond to changes in the work incentives of awarded applicants. This implies that the substantial changes in application cohort effects are almost entirely driven by compositional changes of applicants. Again, this highlights the importance of self-screening among potential applicants as a driver of the observed changes in employment rates. Finally, a substantial part of application cohort effects is explained by changes in demographic variables and the initial labor market position of applicants. As far as we can infer from the inclusion of observed controls, there is a general worsening in the labor market position of application cohorts that are more likely to have flexible contracts. This finding resembles e.g. Autor and Duggan (2003), Von Wachter, Song, and Manchester (2011), and Maestas, Mullen, and Strand (2013) who argue there is a declining demand for low-skilled workers with health conditions in the US.

The remainder of the paper is organized as follows. Section 2 describes the Dutch DI system, together with the relevant reforms and their expected effects. Section 3 provides a description of the selected data and Section 4 contains the estimation strategy. Section 5 presents the results of the analysis before Section 6 concludes.

\section{Institutional Background}

This section describes the main characteristics of the Dutch DI system and the two major disability reforms since 1999: the Gatekeeper Protocol (in Dutch: Wet verbetering Poortwachter) and the WIA (in Dutch: Wet Werk en Inkomen naar Arbeidsvermogen). From now on, we refer to these reforms as the GKP and WIA, respectively. When explaining the effects of the reforms, a particular interest lies in the distinction between compositional effects and incentive effects.

We define compositional effects as changes in the average employment rates that result from changes in the composition of new cohorts of DI applicants. For DI applicants, these changes stem from changes in self-screening and work resumption in the waiting period before the DI decision. Incentive effects are defined as changes in individual employment rates as a response to changes in the work incentives for awarded DI applicants, measured after the DI award decision. 


\subsection{DI in the Netherlands}

The Dutch DI program covers income losses resulting from both occupational and non-occupational injuries of all employed workers. Sick-listed workers apply for DI benefits at the end of the waiting period of absence. The employer is obliged to continue full wage payments in this period. The waiting period was extended from one to two years in 2004.

After application, the National Social Insurance Institute (NSII) determines the degree of disability of workers. To this end, medical examiners assess the limitations of applicants and vocational experts subsequently select occupations with corresponding wages to determine the residual potential earning capacity. The degree of disability then equals the lost potential earning capacity as a fraction of pre-disability earnings. Until 2006, the applicant was awarded DI benefits if the degree of disability exceeded the threshold of $15 \%$. This threshold was increased to $35 \%$ as part of the WIA reform in 2006. Workers with a degree of disability between 35 and $80 \%$ are awarded partial DI benefits and those with losses of more than $80 \%$ receive full benefits. Partially disabled receive 70 percent of their loss of earnings capacity and fully disabled receive 70 percent of their pre-disability earnings.

With its broad coverage, generous benefits and limited self-screening, the Dutch DI system laid the ground for a continuous increase in DI enrollment. Around the turn of the century, DI enrollment peaked at about $12 \%$ of the insured working population (Koning and Lindeboom 2015). Figure 1 shows that annual DI application rates then ranged between 1.2 and $1.4 \%$ of the working population. The first substantial drop in both DI application and awards occurred in 2003, at the start of the GKP reform. Using a discontinuity-in-time regression, Godard, Koning, and Lindeboom (2019) find that the effect amounted to a 40 percent reduction in the DI applicant rate. The second major decrease in DI application and award rates is observed since 2005. While this drop initially demarcates the mechanical effect of the extension of the sickness period to two years in 2005, the new disability law (WIA) led to persistently lower DI inflow rates. ${ }^{3}$ In what follows, we discuss both the GKP reform and the WIA reform in more detail.

3 Albeit that the reform extended the waiting period to two years, some workers still applied for DI in 2005 due to (administrative) delays. For instance, waiting periods could be extended due to a lack of integration efforts. 


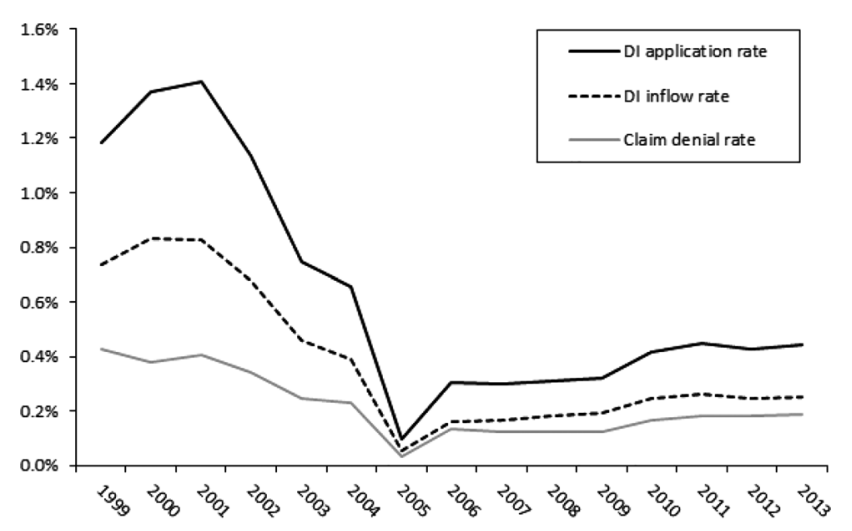

Figure 1: Annual DI application rate, inflow rate and claim denial rate of total insured working population, 1999-2013.

Source: Statistics Netherlands.

\subsection{Stricter Screening: The GKP Reform (2003)}

The GKP reform has affected the screening process for new DI application cohorts since 2003. ${ }^{4}$ The GKP stipulates the responsibilities of both the worker and the employer for sickness spells lasting at least six weeks. This means the responsibility of reintegrating sick workers during the waiting period was removed from the NSII, which since then acts as a gatekeeper at the moment of DI claim. Figure 2 provides an overview of the steps of the application process towards entering DI under the GKP. ${ }^{5}$ After six weeks of absence, the worker and the employer must draft a rehabilitation plan together which is based on an assessment of cause of disability, functional limitations and the likelihood of work resumption. The rehabilitation plan should be approved by a caseworker of the NSII in the eighth week of absence, after which it is binding for both parties. The worker can apply for DI benefits if work resumption is not established before the end of the waiting period and when all requirements of the GKP have been met. If not, the wage continuation period may be extended with one year at maximum.

4 In 2003, the start of the GKP went together with the abolishment of DI experience rating for smaller firms - see De Groot and Koning (2016). As this reform affected only a small share of the working force in the Netherlands, the overall effects on DI applications are small.

5 Note that the figure is relevant under the (current) disability scheme with an absence period of two years. In the year the GKP came into force, the waiting period was one year. 


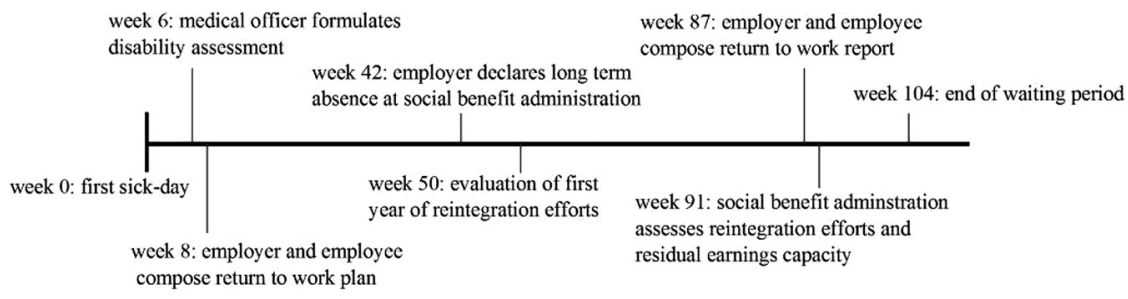

Figure 2: GKP conditions in the sickness waiting period.

There is strong evidence that the GKP changed the composition of DI applicants. The increased rehabilitation efforts did not only increase the likelihood of work resumption in the absence period that precedes DI claims for workers with better employment prospects, but also induced self-screening among those workers with less severe health conditions (De Jong, Lindeboom, and Van der Klaauw 2011; Godard, Koning, and Lindeboom 2019). ${ }^{6}$ Both these mechanisms have resulted in a sample of DI applicants that are probably more deserving, with worse health conditions. ${ }^{7}$

\subsection{The New Disability Law: WIA (2006)}

The main goal of the WIA reform of 2006 was to stimulate workers with less-severe impairments to exploit their residual earnings capacity. The idea was that three policy changes would contribute to this: (i) increased self-screening through an extension of the waiting period from one to two years; (ii) stricter eligibility, as the threshold for DI receipt was increased to 35\%; and (iii) differentiated benefits for severely disabled and applicants with sufficient remaining earnings capacity.

First, the extension of the waiting period from one to two years implied another increase in the costs of wage continuation and all other costs inherent

6 De Jong, Lindeboom, and Van der Klaauw (2011) evaluate a large-scale experiment in the Netherlands to study the effects of increased screening. They find that this induces employers to increase reintegration activities, which in turn increases work resumption rates during sickness absenteeism. They argue that those higher rates are induced by self-screening among the potential applicants.

7 Koning and Lindeboom (2015) argue that the increased application costs of the GKP may also have had adverse effects on the individual employment rates of disabled workers. The increased responsibilities and the risk of extension of wage sanctions - i.e. the increase of the wage continuation period - may have discouraged employers to hire workers with disabilities (see also Hullegie and Koning 2018). 
with the GKP. ${ }^{8}$ Following similar arguments as for the introduction of the GKP, one would expect this extension to increase work resumption and self-screening in the waiting period before DI application.

As a second part of the WIA, the threshold of the degree of disability for eligibility was increased from 15 to 35 percent of pre-disability earnings. Van Sonsbeek and Gradus (2012) argue that this implied a drop in DI inflow rates of roughly 20 percentage points. With a substantially lower share of beneficiaries with partial benefits, it is expected that the average employment rate among the total group of beneficiaries has declined. This compositional effect may have been strengthened by increased self-screening among (potential) applicants with mild health conditions.

Third, the WIA differentiates between fully and permanently disabled workers (IVA) and partially and/or temporary disabled workers (WGA) for which strong financial incentives were introduced. Workers in the WGA scheme receive 70 percent of their lost earnings during the first period of benefit receipt ('wagerelated related benefits'). Depending on the work history, this period lasts 38 months at maximum. Next, WGA beneficiaries continue receiving the same benefit level if and only if they exploit at least 50 percent of their earnings capacity; if not, the benefit is based on the statutory minimum wage. Benefits for partially disabled workers thus function as a wage subsidy that incentivizes them to work. ${ }^{9}$ Koning and van Sonsbeek (2017) find that the incentive change for partially disabled workers increases the employment incidence with 2.6 percentage points. ${ }^{10}$ Still, the overall effect of the increase in incentives is probably smaller than this, as wage subsidies are targeted at partially disabled workers - constituting about one quarter of the total DI inflow - and are relevant in the second period of benefit receipt only (Koning and Lindeboom 2015). ${ }^{11}$

Overall, the GKP and the WIA reform most likely affected the composition of the pool of new DI applicant cohorts. Increases in self-screening and increases in work resumption in the absence period probably have resulted in a smaller sample

8 Godard, Koning, and Lindeboom (2019) argue that GKP costs vary between 0.23 and 0.43 of the total wage sum of firms in the Netherlands.

9 For a detailed explanation of the functioning and consequences of the wage subsidy, we refer to Koning and van Sonsbeek (2017).

10 Kantarci, van Sonsbeek, and Zhang (2019) find somewhat smaller employment effects, comparing sick-listed worker cohorts that fell under the old and new disability scheme, respectively. In their study, the effect estimate of work incentives can be interpreted as an upper bound, as it also captures the effect of the waiting period extension from one to two years.

11 The wage subsidy may have induced perverse work incentives for fully and temporary disabled workers in the WGA scheme, as switches to the partial scheme inhibit the risk of sizable declines in benefits (Koning and Lindeboom 2015). 
of DI applicants with more severe health conditions and lower employment rates. Since the reforms affected new cohorts, we expect that these effects are mirrored by discrete jumps in cohort effects, rather than gradual changes stemming from secular labor market and health trends. For applicants who were awarded benefits, the WIA reform also changed the incentive to work. Accordingly, positive changes in relative cohort employment effects of awarded and rejected applicants may be indicative of incentive effects. Taken together, our interest thus lies in employment changes stemming from both selection and incentive effects of the reforms.

\section{Data}

\subsection{Data Sources}

We use individual-level data on all DI applications between 1999 and 2013 from the administrative records of the NSII. Application cohorts from these years are followed between 1999 and 2016, containing information on the award decision and date, the diagnosed impairment and the assessed degree of disability. ${ }^{12}$ Medical diagnoses are grouped by impairment type (mental, musculoskeletal, respiratory, endocrine, cardiovascular, nervous system and other impairments). ${ }^{13}$ The degree of disability is given by intervals (<15\%, 15-34\%, 35-44\%, 45-54\%, 55-64\%, $65-79 \%, \geq 80 \%)$.

We merge the application data with administrative data of Statistics Netherlands of the full Dutch population between 1999 and 2016. This yields individualyear data covering a sufficiently long period to assess the long-term effects of both the GKP and WIA reform. The Census Register contains information on the personal characteristics, such as gender, month of birth and death, and nationality. The tax records provide information (in 2015 Euros) on annual gross earnings and receipt of unemployment, disability, and social assistance benefits. We define an individual as employed in a specific year when he or she received positive wage earnings. For employed individuals we also observe the contract type (permanent or temporary) and sector of employment (70 in total).

In total, we observe 1,183,186 individual applications between 1999 and 2013. For our empirical analysis, we exclude reapplications, workers that are younger

12 After 2007 we observe a shift from rejections due to insufficient degree of disability to rejections for 'unknown' reasons (see Figure A.10). This probably reflects administrative changes, as the medical assessment was unchanged and rejection rates remained more or less constant. Our analysis therefore does not differentiate between different reasons for rejection.

13 The distribution of impairment groups by application cohorts is shown in Figure A.11. 
than 18, older than 65 or deceased at the time of application and workers for which the year of application or award decision was unknown. ${ }^{14}$ This reduces our sample to 962,356 observations. Attrition from this longitudinal sample stems from the occurrence of deaths and migration.

\subsection{Descriptive Statistics}

Table 1 presents descriptive statistics of employment and earnings of rejected and awarded applicant cohorts before and after the DI decision. We separate the total sample of applicants in three sub-samples: (i) application cohorts unaffected by the reforms, 1999-2002; (ii) application cohorts covered by the GKP but not by the WIA, 2003-2005; and (iii) application cohorts subject both to the GKP and the WIA, 2006-2013. ${ }^{15}$ The table shows that rejected and awarded DI applicants with full benefits have similar pre-disability employment rates two years before the DI assessment. Inherent with the eligibility conditions for DI, these rates are close to $100 \%$. Applicants awarded partial benefits have higher pre-disability earnings and have more often a permanent contract than those rejected and those awarded full benefits. As expected, awarded applicants experience drops in income from earnings that are more sizable than for rejected applicants. Awarded applicants tend to be more often male, older and show higher mortality rates than rejected applicants. Over the years, we also observe substantial changes in the employment rates and the composition of DI applicants. Most notably, in the last time frame (2006-2013) applicant cohorts show markedly lower employment rates two years after application. This drop is most sizable for applicants awarded full DI benefits.

To shed light on longitudinal patterns, Figure 3 depicts the evolution of employment rates of applicant cohorts before and after the award decision. Figure 4 shows a similar graph for separate samples of rejected, partially awarded and fully awarded applicants, with separate panels for the three regimes as in Table 1. From the figures, four general observations stand out. First, employment rates generally increase up to two years before the award decision and decline thereafter. While the initial increase follows from the eligibility conditions inherent to the Dutch DI system, the subsequent decline follows from the start of the absence period that precedes the award decision. Second, we observe large

14 The vast majority of the omitted applications is excluded due to the year of application being unknown $(74,761)$ or the observation of multiple records for the same individual $(134,015)$. In the latter case, we only selected the first application.

15 The GKP affected sick-listed workers as from 2002. Hence, DI applicants of 2002 are not affected. Likewise, the extension of the waiting period from one to two years affected workers that became sick from 2004 onwards. 


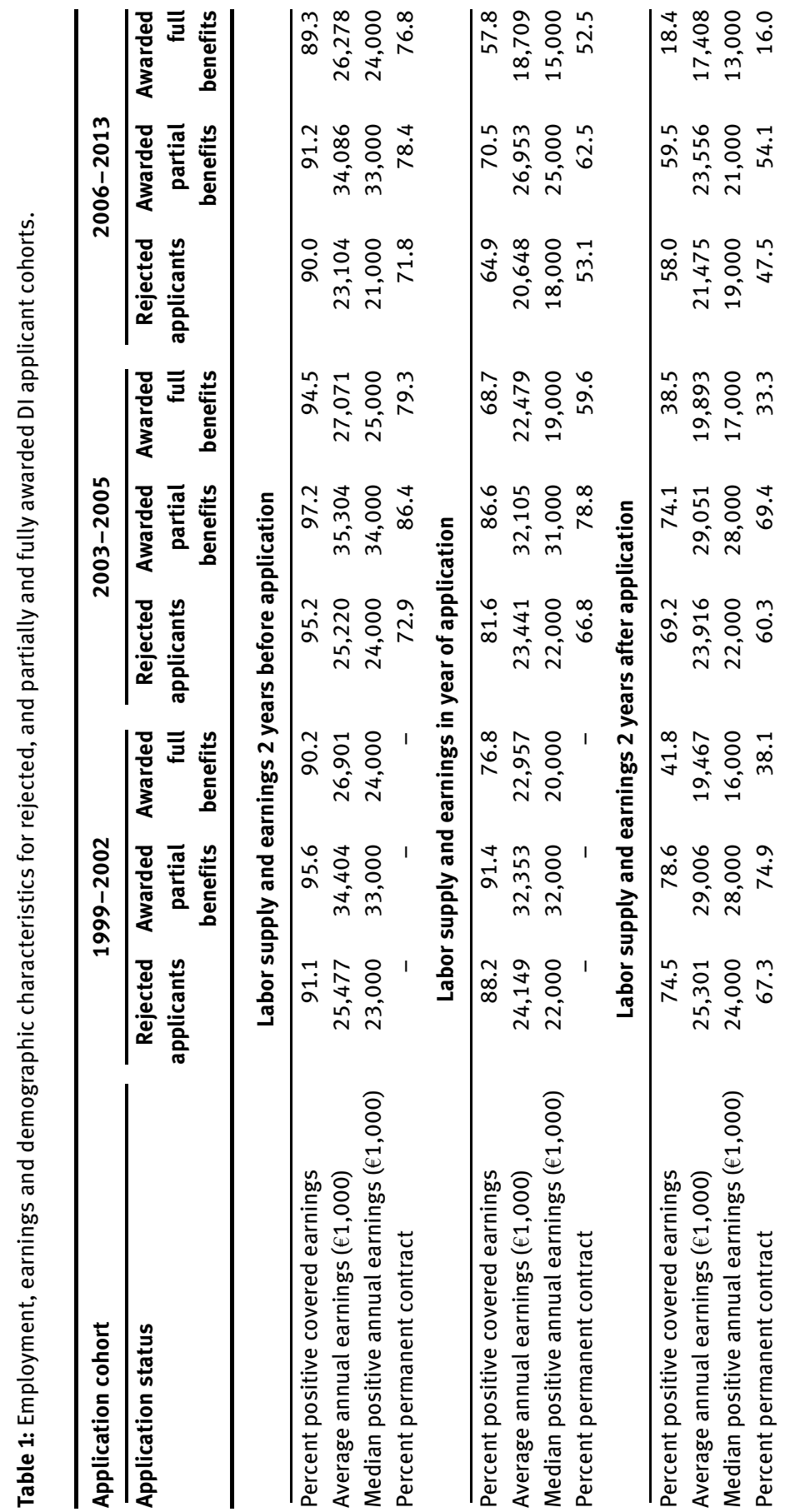




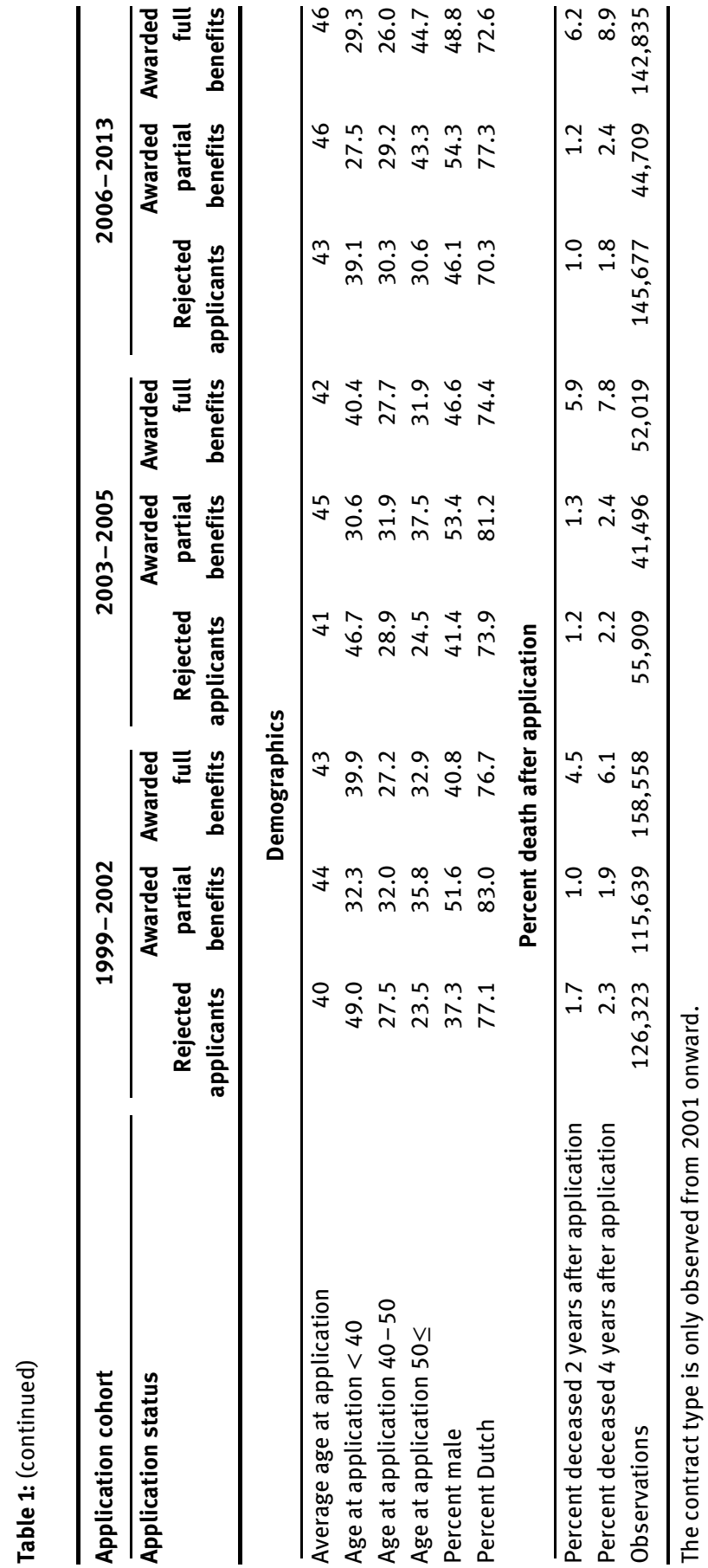




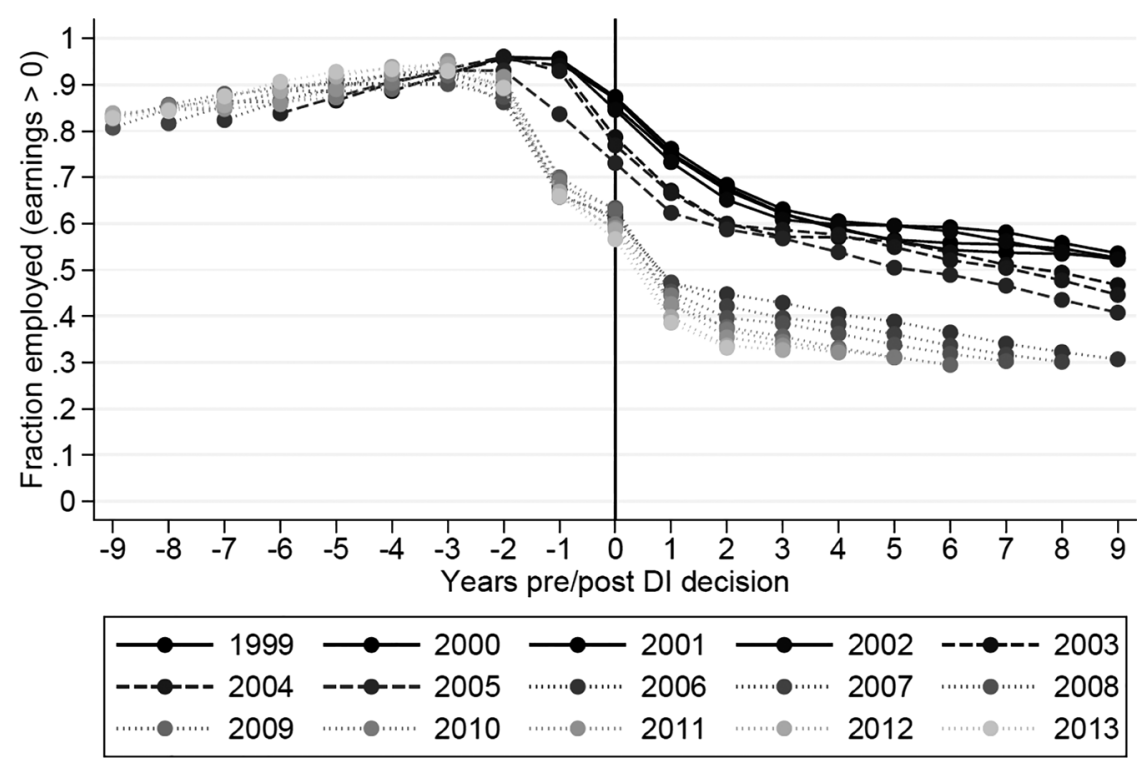

Figure 3: Annual fraction employed DI applicants before and after the award decision, stratified by application year (1999-2013).

jumps in employment rates in the years the two reforms were implemented, but employment rates are roughly constant within the time periods of 1999-2002 and 2003-2005. This suggests that changes in employment rates until 2006 can largely be linked to the GKP and WIA reform. Third, we observe changes in the employment patterns of new application cohorts after 2006, the year the new disability law came into force. Since then, a large share of the decline in employment is already observed in the absence period, two years before the disability decision. Finally, since 2006 the employment rates of successive cohorts gradually decreased with virtually constant between-cohort employment differences. Following the eyeball test suggested by Voas and Chaves (2016), it is unlikely that elapsed duration effects and period effects cancel each other out in such a way that there are constant employment differentials. The driving factor behind the declining employment rates is therefore most plausibly the presence of cohort effects and not combined period and elapsed duration effects.

\subsection{Comparing Rejected and Awarded Applicants}

Following Bound (1989), we proxy the discouraging impact of DI benefits by the difference in employment rates of rejected and awarded applicants. Since the 
Panel A. Annual fraction employed of rejected DI applicants

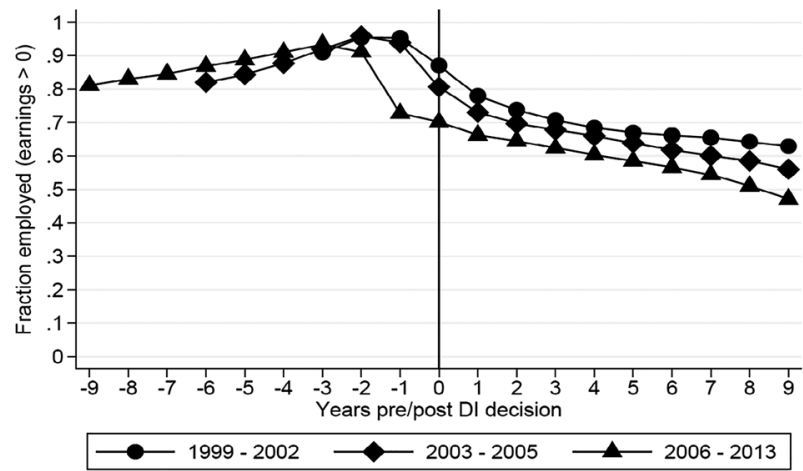

Panel B. Annual fraction employed of applicants awarded partial DI benefits

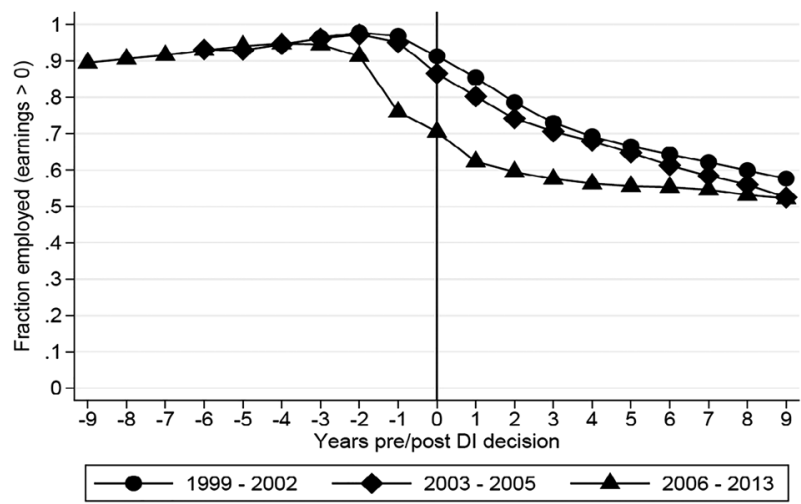

Panel C. Annual fraction employed of applicants awarded full DI benefits

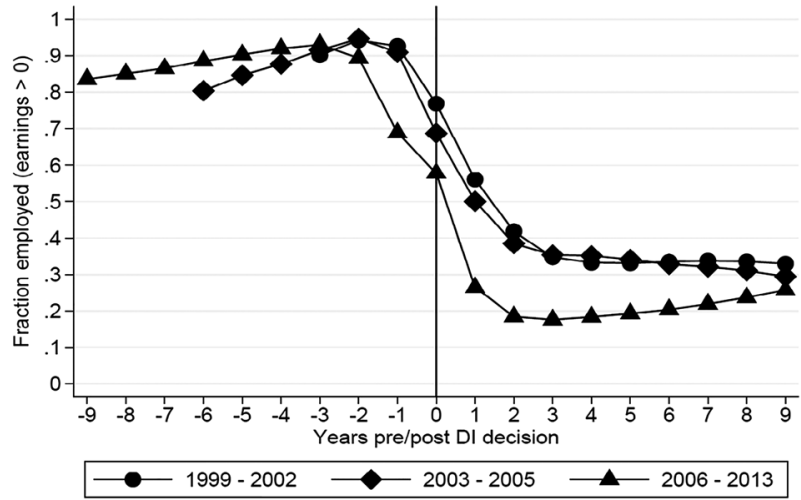

Figure 4: Annual average employment rates of rejected, partially and fully awarded DI applicant cohorts for three time periods, before and after the award decision. 
severity of health impairments is likely stronger among accepted applicants, the difference in employment rates - the 'Bound estimate' - probably provides an upper bound of the discouraging impact. Figure 5 presents annual changes in the Bound estimate for the Netherlands for annual application cohorts, measured three years after the award decision. ${ }^{16}$ Panel (A) shows the annual Bound estimates that follows from comparing rejected and all awarded applicants. Rejected applicants show a gradual decline in the employment rates three years after application, contrasting to the change in employment rates for awarded applicants shows a dramatic decline in 2006, when the WIA came into force. After 2006, the Bound estimate is about 30 percentage points, which is in the ballpark of estimates obtained for SSDI benefits. ${ }^{17}$

To reduce the supposedly positive bias stemming from differences in the severity of impairments, we next limit the sample of awarded applicants to those with partial DI benefits. Panel (B) of Figure 5 shows that these two groups have very similar downward employment patterns. The corresponding Bound estimate becomes small and even negative, ranging between -2 and -5 percentage points. This negative sign originates from the fact that applicants with higher predisability earnings are more likely to have a strong labor force attachment and experience a higher percentage drop in earning capacity. Similar arguments are put forward by Maestas, Mullen, and Strand (2013), who show that rejected SSDI applicants typically have lower pre-employment rates. Finally, panel (C) shows the employment rates for application cohort samples that are classified by degree of disability (below 35\% or between 35 and 80\%) and not by benefit outcome. Until 2006, employment rates of both groups are virtually equal to each other. Thereafter, the patterns are the same as in panel (B).

16 This gives a sufficiently long time delay to assess long-term employment rates of these cohorts. 17 Bound (1989) finds a difference in employment rates one year after application of between 26 and 30 percentage points for applicants aged 45-64. Von Wachter, Song, and Manchester (2011) shows that the Bound estimate amounts to more than 35 percentage points for applicants aged 30-44. Bound, Burkhauser, and Nichols 2003 estimates a difference three years after application of 20 percentage point. These results are similar to Chen and Van der Klaauw (2008) who show a reduction of the labor force participation of 15-18 percentage points. 
Panel A. Employment rates of rejected applicants and awarded applicants

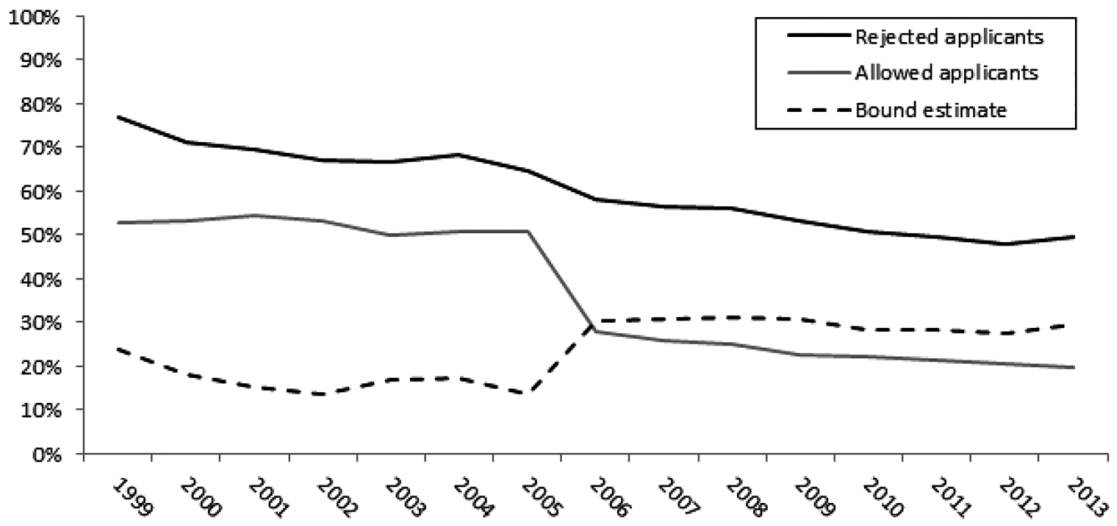

Panel B. Employment rates of rejected and partially awarded applicants

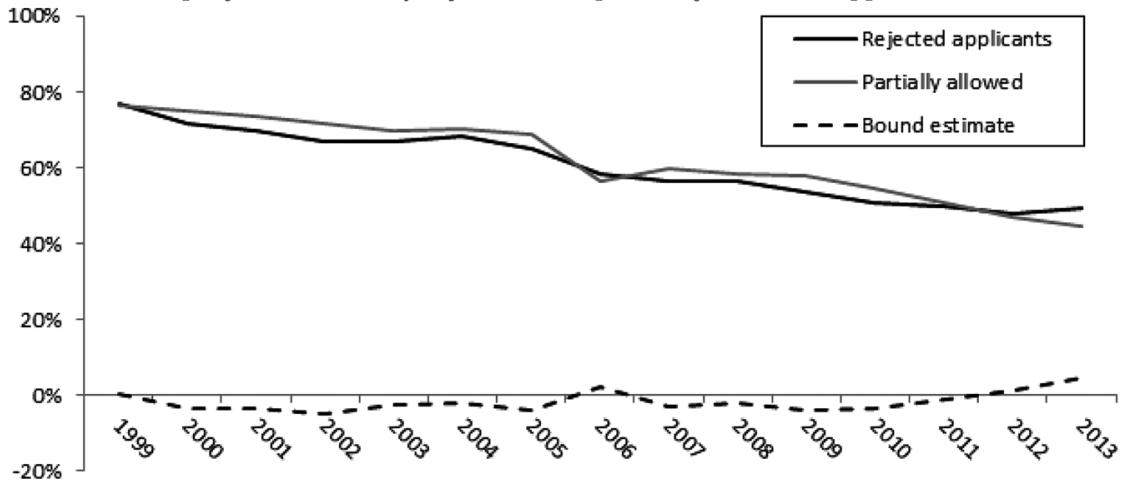

Panel C. Employment rates of applicants with degree of disability of $<35 \%$ and 35 $80 \%$

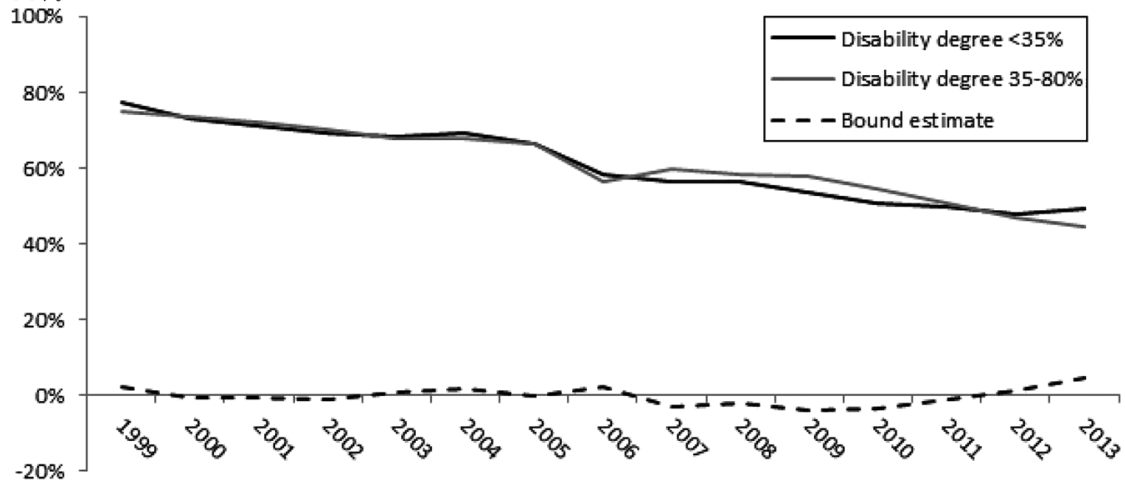

Figure 5: Annual employment rates and Bound estimates for different application cohort samples between 1999 and 2013, measured three years after the DI decision. 


\section{Empirical Strategy}

\subsection{Specification}

The aim of this paper is to decompose the mechanisms underlying the substantial decline in the employment rates of DI applicants. To this end, we propose a two-step analysis with Age-Period-Cohort (APC) models. First, we decompose employment trends into changes in the effect of the elapsed duration since application (the 'age' effect), time period effects and application cohort effects. Second, we further decompose application cohort effects into compositional and incentive effects, using a Difference-in-Differences (DiD) approach with distinct effects for awarded and rejected applicants.

We specify the APC model for the incidence of employment $E$ for all DI applicants in our sample, measured for post-application years. $E$ is equal to one while working and zero otherwise.

$$
E_{i t, \tau}=\alpha_{t-\tau}+\pi_{t}+\gamma_{\tau}+\epsilon_{i t}
$$

with $t \geq \tau$. In Eq. (1), the employment status $E$ of individual $i(i=1, \ldots, N)$ in year $t$ $(t=1, \ldots, T)$ with a DI decision in year $\tau(\tau=1, \ldots, \mathcal{T})$ is determined by the number of years after application (i.e. the 'age' effect), a calendar year ('period') effect and an application cohort effect. Note that we have $T=18$ years (1999-2016) and $\mathcal{T}=15$ application cohorts (1999-2013) in our sample. Age, period and cohort effects are denoted by the vectors $\alpha, \pi$ and $\gamma$, respectively. Regarding cohort effects, it is important to stress that reforms affected new application cohorts only. Discontinuous changes in application cohort effects may therefore indicate reform effects. Without age as a control variable, the 'age' effect equals the effect of aging and the elapsed duration since application. ${ }^{18}$ Finally, $\epsilon$ is an error term.

In Eq. (1), application cohort effects estimates represent both compositional changes among applicant cohorts and incentive changes among the sub-sample of awarded applicants. To further disentangle these two effects, we therefore extend the APC model with distinct age, period and cohort effects for awarded and rejected DI applicants. Specifically, we define $A_{i, \tau}$ as a dummy that is equal to one if DI applicant $i$ in the application year cohort $\tau$ is awarded benefits, and zero otherwise. This yields the following specification:

$$
E_{i t, \tau}=\left(1-A_{i, \tau}\right)\left\{\alpha_{t-\tau}^{0}+\pi_{t}^{0}\right\}+A_{i, \tau}\left\{\alpha_{t-\tau}^{1}+\pi_{t}^{1}\right\}+\gamma_{\tau}+\left(1-A_{i, \tau}\right) \tilde{\gamma}_{\tau}+\epsilon_{i t},
$$

18 We will also estimate model specifications that control for the age of applicants. 
with $\alpha^{0}$ and $\pi^{0}$ denoting age and period effects for the rejected applicants, respectively; $\alpha^{1}$ and $\pi^{1}$ denoting age and period effects for the awarded applicants, respectively; and $\tilde{\gamma}_{\tau}$ as the application cohort effect that is interacted with the award indicator. ${ }^{19} \tilde{\gamma}_{\tau}$ can be interpreted as the Bound estimate for a specific application cohort $\tau$. This estimate controls for the fact that age and period effects may differ between awarded and rejected applicants. Increases in the Bound estimate $(\tilde{\gamma})$ indicate equal decreases in incentive effects; this follows from the fact that the Bound estimate takes awarded applicants as a reference group. Since there is a specific Bound estimate for each cohort year, we refer to $\tilde{\gamma}_{\tau}$ as the unrestricted Bound estimates.

To provide a more structured view on the effect of the reforms in our sample, we next impose the following restrictions on the Bound-estimates, $\tilde{\gamma}$ :

$$
\tilde{\gamma}_{\tau}=\tilde{\gamma}_{0}+I(\tau \geq 2003) \tilde{\gamma}_{\text {gkp }}+I(2006 \leq \tau \leq 2009) \tilde{\gamma}_{\text {wia,st }}+I(\tau \geq 2010) \tilde{\gamma}_{\text {wia,lt }}
$$

with $\tilde{\gamma}_{\text {gkp }}, \tilde{\gamma}_{\text {wia,st }}$ and $\tilde{\gamma}_{\text {wialt }}$ denoting the effect of the GKP reform and the shortterm and long-term effect of the WIA reform on the Bound estimate. ${ }^{20}$ We refer to the combined Eqs. (2) and (3) as the restricted DiD model.

\subsection{Identification}

To estimate the age, period and cohort parameters in our specifications, we essentially build on two sets of usual identifying model assumptions and one additional identifying assumption that is relevant for the specification with distinct effects for awarded and rejected DI applicants. First, it is well-known that the identification of all APC parameters requires a constraint on the linear relationship between age, period and cohort effects. We do so by following Deaton and Paxson 1994, who assume that the average effect of period effects is equal to zero $\left(\Sigma_{1}^{T} \pi_{t}\right.$ $=0)$ and that there is no trend in period effects $\left(\Sigma_{1}^{T} t \pi_{t}=0\right)$. This resembles the idea that time effects reflect transitory business cycle effects. We will challenge this hypothesis in two ways. Most importantly, we will parameterize time effects as a function of business cycle indicators to investigate the robustness of our findings. We also provide a test on non-stationarity of period effects that allows for quadratic time period effects. If quadratic time effects matter, the assumption of stationary time effects is violated.

19 Similar to Eq. (1), note that we impose orthogonality restrictions on $\alpha^{0}$ and $\alpha^{1}$ to estimate all parameters of Eq. (2).

20 In light of the long time period that is observed after the WIA reform, we allow for a more flexible specification that distinguishes short-term from long-term effects. Obviously, the common trends assumption is more stringent for the long-term effects. 
Our second key assumption is that age, period and cohort effects are orthogonal and additive. Most notably, this assumption implies that reform effects are captured by cohort effects that are constant in the years after application. Hence, we do not allow the elapsed duration profiles to change due to reforms. ${ }^{21}$ To test for the sensitivity of our findings, we will therefore consider more flexible model specifications with distinct age profiles for time periods with different policy regimes. In doing so, we compare the accumulated cohort effects for this model with the model that assumes constant age profiles over the full time period under investigation.

Third, the identification of incentive effects in Eq. (2) requires an additional assumption. Specifically, we assume common compositional changes for awarded and rejected applicants that lead to common employment trends stemming from compositional changes. We argue this assumption is plausible, since the medical assessment and the derivation of degrees of disability did not change fundamentally in the time period under consideration. Given the common compositional trends assumption, the increase in employment rates that is specific to the awarded applicants can be interpreted as the effect of changes in benefit conditions. This "DiD" increase is the equivalent of the change in the Bound estimate.

In light of the eyeball tests in Section 3, the assumption of common changes in compositional effects is more plausible if rejected applicants are compared to awarded applicants which are (also) deemed to have substantial residual earnings capacity. This calls for the estimation of models where we compare partially awarded applicants to rejected applicants or compare samples that are stratified by the degree of disability. As far as there are secular trends or reforms with compositional effects, applicants with similar earnings capacities are likely to be affected equally by this. Another way to test for common changes in compositional effects will be to compare model outcomes with and without the inclusion of control variables that were discussed earlier. If compositional changes affect awarded and rejected applicants equally, estimates should not be affected.

In what follows, we start by presenting OLS estimation results of Eqs. (1) and (2) without (time constant) control variables that may or may not embody application cohort effects. As a result, the cohort estimates show the composite impact of all time-invariant variables that affect employment. Later on we also estimate model versions that include dummies for five-year age groups, gender, ethnicity, impairment types and the pre-disability employment status as controls,

21 Likewise, we model common time effects for DI applicants that are observed in the first and in later years after the application moment. 
so as to obtain insight in the sources of compositional changes that drive cohort effects. ${ }^{22}$

\section{Estimation Results}

\subsection{The Age-Period-Cohort Model}

Figure 6 graphically presents the elapsed time (or: 'age'), period and cohort profiles of the employment for our full sample of DI applicants for four model variants. Following from Eq. (1), our primary focus is on the APC-DP model as a benchmark; the respective results are indicated by the black, solid lines. To start with, our benchmark model shows elapsed time profiles since the DI decision - i.e., the 'age'-effect - that display a kinked pattern (see panel (A)). Since individual controls are not included, the estimates reflect the joint long-term effect of application over time and the actual aging of applicants. The drop in employment is largest in the first and second year after the DI decision, amounting to a decrease of nearly 20 percentage points. In this period applicants awarded benefits may leave the labor market and a large fraction of rejected applicants is laid off by their employer. ${ }^{23}$ Subsequently, the employment rate of applicants declines with approximately 2 percentage points per year, such that the total decrease after 17 years equals roughly 45 percentage points.

Panel (B) of Figure 6 points at small period effects. The spread of period effects is less than 5 percentage points, whereas the time and cohort effects add up to about 45 and 30 percentage points, respectively. When comparing these findings to those of the AC model (without period effects), transitory period effects explain a negligible part of the variation in the employment. ${ }^{24}$ Still, the small period effects of the DP model mimic business cycle patterns seemingly well, with peaks in 2001 and 2008.

Panel (C) indicates sizable application cohort effects, particularly when the GKP and WIA came into force. Changes in application cohort effects add up to a 30 percentage points difference between 1999 and 2013. This difference largely

22 We use the employment status in the year before application. We also estimated models using the employment status two years before application for cohorts after the WIA reform, taking into account that these applicant cohorts face a longer waiting period. This yields similar results.

23 Note that this contrasts to the SSDI system, where applicants typically have no (substantial) earnings from employment to begin with.

24 The $R$-squared of the APC-DP model is 0.0683 and for the AC model 0.0680 , respectively. 


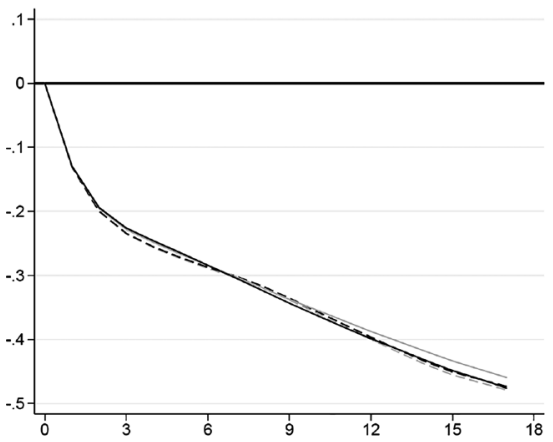

(a) Age effects

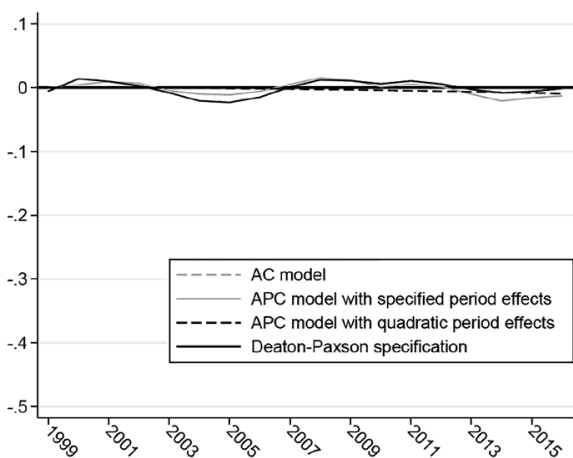

(b) Period effects

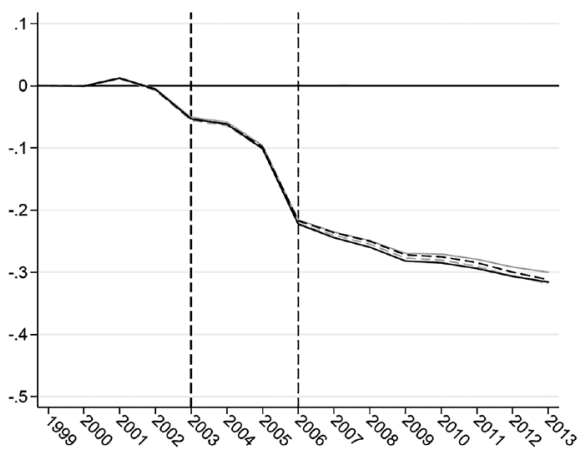

(c) Cohort effects

Figure 6: Elapsed time ('age'), period and application cohort effects on the employment of DI applicants.

Note: The figure displays the results of the following four models: (i) Age-Cohort (AC) model, (ii) APC model with the period effects depend on the ratio of vacancies to unemployment and the employment rate of low-educated individuals, (iii) APC model with the period effects specified as a quadratic function, and (iv) Deaton-Paxson specification. The sample consists of all workers who applied for DI benefits in the Netherlands between 1999 and 2013.

stems from a 4 percentage points drop in 2003 and another drop of about 13 percentages points in 2006. Again, these discrete changes suggest the impact of the Gatekeeper and the WIA reform. The cohort effects also show a continued decline in the years after the start of the WIA in 2006. In total, more than half of the change in cohort effects is confined to the reform years 2003 and 2006.

\subsection{Robustness}

In line with the orthogonality assumptions that were discussed earlier, we investigate the robustness of our findings. Since the DP-model does not allow 
for non-transitory period effects, our first concern is that structural trends are absorbed by the age and cohort effect estimates. We assess the stringency of the orthogonality assumptions of the DP model in two ways - the results are (also) shown in Figure 6. First, we estimate an APC model where period effects are specified as a quadratic function and age and cohort effects as (non-parametric) step functions. Albeit that this specification does not result in the (full) identification of APC effects, it enables us to estimate a part of identifiable non-linear period effects that may be non-transitory. Accordingly, the coefficient of the quadratic period effect, together with changes in age and cohort effect estimates, provides us with conservative tests on the existence of non-transitory period trends. The concerning coefficient is statistically significant, but the dashed black lines in Figure 6 show its magnitude is negligible and the accumulated application cohort and age effects are very similar to those for the DP model. Second, we consider parametric specifications where period effects depend on the ratio of vacancies to unemployment and employment rates of low-educated individuals. Arguing that low-educated individuals are over-represented among DI applicants, this auxiliary information can be used to proxy period effects that may also may show more structural trends e.g. arising from skill-biased technological change (SBTC) ${ }^{25}$ We then find one percentage point increase in the employment rate of low-educated workers to be associated with a 0.6 percentage point increase in the period effect. While this estimate is statistically significant, the resulting range of period effects is comparable to those for the APC-DP model.

As stated earlier, our benchmark model also imposes orthogonality assumptions on the interrelation between age, period and cohort effects. As a result, changes in elapsed duration profiles induced by the reforms are absorbed by applicant cohort effects. We therefore re-estimate the APC model with specifications with distinct age profiles and application cohort effects across three time periods: 1999-2002, 2003-2005, and 2006-2013. The implied changes in accumulated application cohort effects are shown in Figure 7 . The bars in the figure indicate (i) the implied total change in cohort effects for the baseline DP model; (ii) for the AC model (i.e. without period effects); and (iii) for the AC model with distinct age and cohort effects for the three time periods. ${ }^{26}$ The figure shows that the AC model yields application cohort effects for the three time periods that are

25 From 2005 onward, we observe employment rates of disabled individuals in the public scheme for disabled individuals that have no eligibility into the DI scheme (i.e. the 'Wajong'). For this limited time period, this variable did not yield a significant coefficient estimate.

26 Note that the estimation of APC models with distinct age effects would give rise to identification problems of period effects. Since period effects we find are generally small for the total period, setting these equal to zero is not a strong restriction to make. 
1999-2002

2003-2005

$2006-2013$

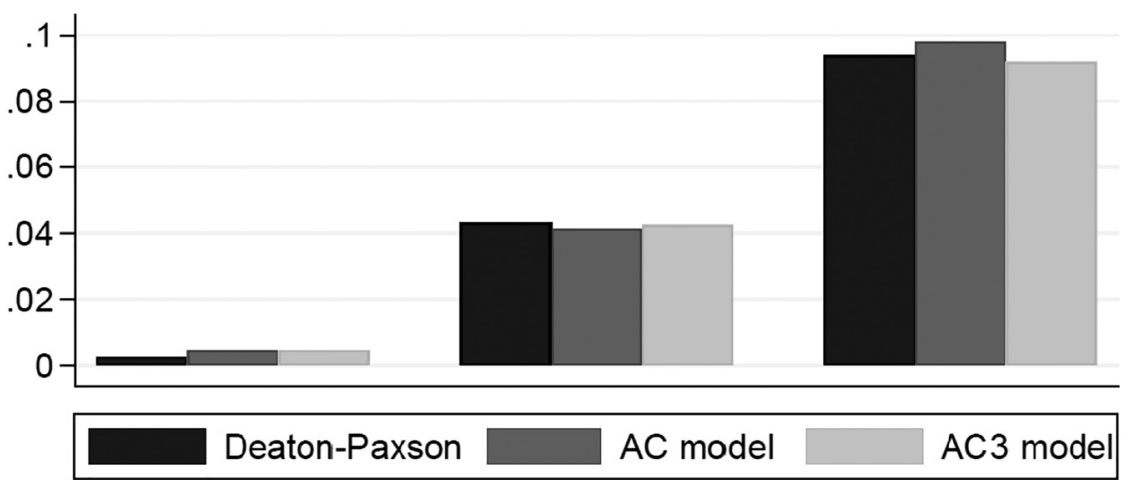

Figure 7: Comparing implied absolute declines in cohort effects of three models, measured for 1999-2002, 2003-2005, and 2006-2013.

Note: The three models: (i) Deaton-Paxson specification, (ii) AC model, and (iii) AC model with specific age and control effects for each of the three time periods.

virtually equal to those of the DP model. The negative application cohort effects after 2006 represent either learning or adaptation effects of the WIA reform or point at a secular trend in health and labor market conditions that are specific to new applicant cohorts.

\subsection{Decomposing Incentive Effects}

Table 2 presents the estimation results for the incentive effect of the GKP and WIA reforms, $\tilde{\gamma}_{\tau}$, using the restricted (DiD) model of Eqs. (2) and (3). Recall that the incentive effect measures changes in the Bound estimate, with positive changes pointing at a worsening of the employment probability of awarded applicants (and reverse). The findings for the restricted model are complemented with the unrestricted Bound estimates for all annual application cohorts - as shown in Figure 8. For both the restricted and the unrestricted model, we compare (differenced) application cohort effects of the following groups: (i) rejected applicants versus awarded applicants with partial benefits in columns (1 and 2); (ii) applicants with a degree of disability below 35\% versus applicants with a degree of disability between 35 and $80 \%$ in columns ( 3 and 4); (iii) applicants with degree of disability below $35 \%$ versus applicants with a degree of disability between 35 and $55 \%$ in columns (5 and 6 ). 
Table 2: DiD incentive effects of the Gatekeeper Protocol (GKP) and short-term and long-term incentive effect of the WIA reform.

\begin{tabular}{|c|c|c|c|c|c|c|}
\hline & \multicolumn{2}{|c|}{$\begin{array}{c}\text { Rejected vs } \\
\text { partially allowed }\end{array}$} & \multicolumn{2}{|c|}{$\begin{array}{l}\text { Degree of disability } \\
<35 \% \text { vs. } 35-80 \%\end{array}$} & \multicolumn{2}{|c|}{$\begin{array}{l}\text { Degree of disability } \\
<35 \% \text { vs. } 35-55 \%\end{array}$} \\
\hline & (1) & (2) & (3) & (4) & (5) & (6) \\
\hline$\tilde{\gamma}_{\mathrm{gkp}}$ & $\begin{array}{r}-0.005^{*} \\
(0.00)\end{array}$ & $\begin{array}{r}-0.005^{*} \\
(0.003)\end{array}$ & $\begin{array}{l}-0.001 \\
(0.003)\end{array}$ & $\begin{array}{r}0.000 \\
(0.003)\end{array}$ & $\begin{array}{l}-0.001 \\
(0.004)\end{array}$ & $\begin{array}{l}-0.001 \\
(0.004)\end{array}$ \\
\hline$\tilde{\gamma}_{\text {wia,shortterm }}$ & $\begin{array}{l}0.009^{*} \\
(0.005)\end{array}$ & $\begin{array}{r}0.026^{* * *} \\
(0.004)\end{array}$ & $\begin{array}{r}-0.009^{*} \\
(0.005)\end{array}$ & $\begin{array}{r}0.013^{* * *} \\
(0.004)\end{array}$ & $\begin{array}{l}-0.005 \\
(0.006)\end{array}$ & $\begin{array}{r}0.013^{* * *} \\
(0.005)\end{array}$ \\
\hline$\tilde{\gamma}_{\text {wia,longterm }}$ & $\begin{array}{r}0.029 * * * \\
(0.004)\end{array}$ & $\begin{array}{r}0.032^{* * *} \\
(0.004)\end{array}$ & $\begin{array}{r}0.018^{* * *} \\
(0.004)\end{array}$ & $\begin{array}{r}0.025^{* * *} \\
(0.004)\end{array}$ & $\begin{array}{r}0.018^{* * *} \\
(0.005)\end{array}$ & $\begin{array}{r}0.022^{* * *} \\
(0.005)\end{array}$ \\
\hline Controls & - & $\checkmark$ & - & $\checkmark$ & - & $\sqrt{ }$ \\
\hline Observations & $6,730,460$ & $5,561,737$ & $6,736,052$ & $5,567,329$ & $6,193,528$ & $5,095,192$ \\
\hline$R^{2}$ & 0.0642 & 0.2026 & 0.0650 & 0.2030 & 0.0622 & 0.2001 \\
\hline
\end{tabular}

Note: Control variables include individual characteristics (age, gender, ethnicity), impairment types and employment history (employment status, UI benefit receipt and sector of employment). Individual clustered standard errors in the parenthesis. ${ }^{*} p<0.10,{ }^{* *} p<0.05$, ${ }^{* * *} p<0.01$.

The DiD estimates in Table 2 suggest no incentive changes at the start of the GKP reform for all group comparisons. As the GKP aimed at changing the screening process before application, these results are in line with expectations and can be considered as placebo-outcomes. The evidence for the incentive effects of the WIA reform, however, is less clear-cut. As to the effects in the first four years since the reform (i.e. 2006-2009), all model specifications without controls show negligible and only weakly statistically significant estimates of the incentive effects. ${ }^{27}$ The estimates increase somewhat after the inclusion of controls, suggesting that the common compositional cohorts assumption may be violated. For the long-term incentive effects (i.e. 2010-2013), our results indicate decreases of work incentives ranging between 2 and 3 percentage points - i.e. an increase in the Bound estimate - for partially awarded applicants. While these findings may appear more robust than the short-term effects at first sight, the common compositional trends assumption is more stringent for long-term effects.

27 Recall that both Koning and van Sonsbeek (2017) and Kantarci, van Sonsbeek, and Zhang (2019) also find only small causal employment effects of the WIA reform. 
We next move to the unrestricted Bound estimates as shown in Figure $8 .^{28}$ Similar to the graphical inference that was discussed earlier, the initial difference in application cohort effects is negative and fairly constant up till 2005 for all group comparisons. This again underlines the notion that the GKP increased the reintegration responsibilities during the waiting period for all DI applicants. For the WIA reform, again, there is no clear pattern that emerges. Depending on the stratification of groups, the Bound estimate can either stay more or less constant or decrease in 2006 (which implies a positive incentive impact). If any, Figure 8 suggests that the incentive effects of the WIA reform are small. Moreover, it appears unlikely that the increases in the Bound estimate after 2010 can be interpreted as the effect of the WIA reform. Taking a broader perspective, we are safe to say that the accumulated changes in application cohort effects by far cannot be explained by changes in DI benefit incentives.

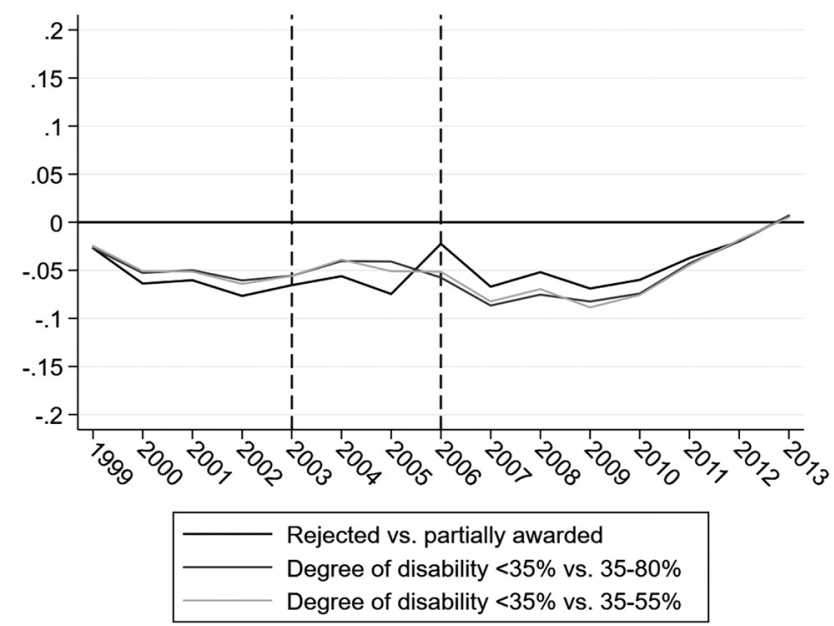

Figure 8: Annual Bound-estimates on employment for the unrestricted APC-DP models Note: The vertical axis displays the parameter estimates of $\tilde{\gamma}_{\tau}$ from Eq. (2). The estimation allows for different age en period effects for rejected and awarded applicants.

28 All parameter estimates of $\tilde{\gamma}_{\tau}$, both without and with controls, can be found in Table A.3 in the Appendix A, together with additional $F$-statistics which follow from multiple testing. 


\subsection{Application Cohort Effects in More Detail}

Our results so far point at sizable compositional cohort effects as the main driving force of employment trends, together with steep elapsed duration effects. We therefore investigate the origins of these cohort effects in three ways: we reestimate the APC-DP model using various sets of controls and for sub-samples, as well as on outcome variables other than employment that are indicative for the labor market performance and health of applicants.

First, Figure 9 shows the results for the DP model with various sets of control variables that are added sequentially: (i) individual characteristics that include dummies for five-year age groups, gender and ethnicity; (ii) impairment types; and (iii) the employment history in the year before application (employment status, UI benefit receipt and the sector of previous employment). The inclusion of control variables causes the elapsed time effect estimates to level out after the first two years. More specifically, the observed change in elapsed time effect estimates in the first two years after application is almost entirely induced by the inclusion of age

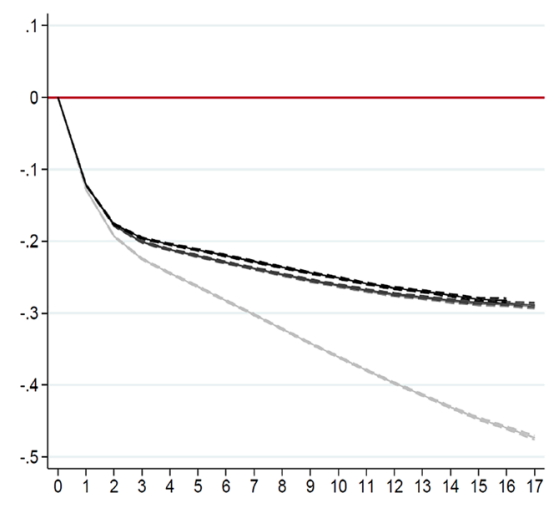

(a) Elapsed time effects

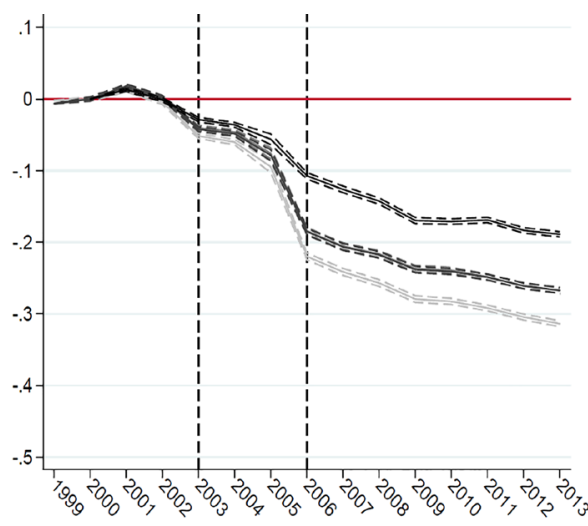

(b) Cohort effects

Figure 9: Deaton-Paxson estimation results on employment of elapsed time ('age') and cohort effects with step-wise inclusion of sets of control variables.

Notes: The base specification (light grey line) is the model without control variables. We subsequently add: (i) dummies for age groups of five years, gender and ethnicity; (ii) impairment types; and (iii) employment status in the year prior application (employment status, UI benefit receipt and sector of employment). The dashed lines outline the 95-percent confidence intervals. The sample consists of all workers who applied for DI benefits in the Netherlands between 1999 and 2013. 
dummies. ${ }^{29}$ We also see substantial reductions in application cohort effects with the control variables, suggesting self-screening effects on the average employment that occur before the DI decision. Specifically, the inclusion of age dummies and the employment status in the year before application reduces the application cohort effects substantially, whereas there are no changes in application cohort effects when including impairment types. Roughly speaking, about 40 percent of the 31 percentage points decline in employment rates of subsequent application cohorts is explained by self-screening on observed variables. As we have a limited set of controls, this estimate should be interpreted as a lower bound for the total effect of self-screening.

Interestingly, the inclusion of controls does not change application cohort effects substantially until 2006. The GKP probably discouraged workers with lesssevere impairments from applying, rather than those with better labor market prospects. By contrast, the instantaneous drop in employment rates at the time of the WIA reform can largely be explained by the screening out of workers with better labor prospects, causing the remaining applicant pool to have less permanent contracts and a higher fraction being unemployed one year before application. ${ }^{30}$ These compositional changes support the idea that the changes in application cohort effects are a representation of increased self-screening during the waiting period. In addition, we find that the gradual further decline in employment after the onset of the WIA reform can partially be explained by gradual compositional changes in observed controls.

Second, we estimated age and application cohort effects of samples that are stratified according to award decisions (rejected, partially awarded, fully awarded), gender, age groups (18-44 vs. 45-64) and impairment types (mental, musculoskeletal, cardiovascular and all other types) - these are all shown in Figure A.13 in Appendix A. In line with expectations, we see larger and initially steeper age profiles for groups with a higher degree of disability, older ages and those diagnosed with cardiovascular disorders. This contrasts with rejected and partially awarded applicants and younger applicants who show more persistent employment profiles after the award decision. As to the application cohort effects, the initial decline since the start of the WIA is more substantial among those awarded full benefits, but next the partially awarded applicants catch up and

29 The results are similar when we use 10-year age groups. The employment rates drop after the applicants reach their retirement age; this effect amounts to more than 20 percentage points.

30 The newer application cohorts are also older (the last cohort is on average 5 years older than the first cohort), more often male (10\%-points) and for a larger share non-native (8\%-points). 
experience a similar aggregate decline. ${ }^{31}$ Changes in application cohort effects are most substantial for workers with mental impairments and already materialize in the year the GKP reform took place. This suggests moral hazard was present among workers with mental impairments, as the GKP implied stronger screening before application. ${ }^{32}$

Finally, Figure A.14 in Appendix A presents age and cohort effects on wage earnings, contract types, Unemployment Insurance (UI) receipt and mortality rates of DI applicants. Panel (A) shows that earnings cohort effect have a similar pattern as the incidence of employment. Application cohort effects accumulate to 10,000 Euro per year, corresponding to 40 percent of the average income at the time of application. This effect is roughly equal to the extensive margin effect on employment. Panel (B) shows that the decline in application cohort effects of the probability on a permanent contract is roughly equal to that for all contracts, suggesting the decline is confined to permanent contracts. This finding underlines the importance of changes in the composition of application cohorts, with recent applicant cohorts having more vulnerable labor market positions. The evidence for UI benefit receipt in panel (C) suggests that application cohorts are more likely to loose (partial) employment. This may point at substitution effects into UI - see e.g. Koning and Van Vuuren (2010), Borghans, Gielen, and Luttmer (2014), and Benitez-Silva, Disney, and Jiménez-Martín (2010). Finally, panel (D) shows that mortality rates among applicant cohorts have increased after the reforms. ${ }^{33}$ All these results highlight the importance of compositional effects among DI applicant cohorts as a driving factor of the changes in employment rates.

\section{Conclusions}

In this paper we expand on Age-Period-Cohort (APC) models to explain changes in the employment rates of Disability Insurance (DI) applicants. We use administrative data of DI application cohorts for the Netherlands, a country that

31 Koning and van Sonsbeek (2017) argue that the stronger work incentives induced by the WIA has increased the relevance of a 'cash-cliff' to the fully and temporary disabled beneficiaries.

32 Moral hazard may have been more important among workers with mental problems as it is a more heterogeneous group, with a high share of conflicts at work that prevent rehabilitation of sick-listed workers.

33 To calculate mortality rates, we follow the approach by Johansson, Laun, and Laun (2014) who use post-application mortality as proxy for ex-ante health. 
experienced major disability reforms that intensified the screening process before application, tightened eligibility conditions and increased work incentives for benefit recipients. Using a Deaton-Paxson specification, we first decompose application cohort effects from period and age effects. The resulting application cohort effects represent the joint effect of (i) compositional changes induced by disability reforms; (ii) compositional changes induced by labor market trends; and (iii) behavioral changes in the employment rate of awarded applicants ('incentive effects') induced by reforms. To separate incentive from compositional effects, we develop a further decomposition that compares the employment rates of awarded applicants to those of rejected applicants. Assuming that compositional cohort effects for employment - both induced by reforms and changes in the labor market - affected both groups equally, the Difference-in-Differences (DiD) estimate of the reforms equals the change in the individual employment probability. This effect can be characterized as incentive effects of the reforms on benefit recipients.

We find that application cohort effects are the key driver of the observed decline in employment rates of DI applicants in the Netherlands. Both secular application cohort trends in the labor market and large instantaneous selfscreening effects induced by reforms affected new applicant cohorts, rather than period effects or changes in work incentives for awarded applicants. Even though the period effects mimic the business cycle, its relevance in explaining employment changes is negligible. Likewise, our further decomposition of application cohort effects into compositional and incentive effects suggests that changes in incentive effects are dwarfed by compositional effects. This highlights the importance of self-screening effects that were inherent with the reforms, with sick-listed workers that were discouraged to apply for DI benefits. Self-screening has dramatically changed the composition DI applicants, with less room for workers with residual earnings capacities who complement their labor income with benefits. Stated differently, the reforms have changed the targeting of the DI benefit scheme, rather than the work incentives.

Our results provide a novel perspective on evaluations that generally point at large inflow and enrollment effects of disability reforms in the Netherlands (De Jong, Lindeboom, and Van der Klaauw 2011; Godard, Koning, and Lindeboom 2019; Koning and Lindeboom 2015). While these reforms have drastically changed the targeting of the DI scheme, the behavioral work impact of changes in the design of DI benefits has only been limited. This resembles recent findings from Haller, Staubli, and Zweimuller (2020), who also argue that reforms that change the eligibility of DI benefits have much stronger consequences for targeting than changes in benefits. Our findings also add to international analyses that suggest a trend of more vulnerable, low-skilled labor market groups becoming applicants for disability benefits (Autor and Duggan 2003; Maestas 2019; Von Wachter, Song, 
and Manchester 2011). Specifically, we find changes in the initial labor market position and sector of employment of applicants as important drivers of the observed decline in employment. This change applies to new applicant cohorts, rather than affecting all individuals that have applied for benefits at some point in time. To some extent, the dominant role of application cohort effects may stem from the relatively strict Employment Protection Legislation (EPL) that prevails in the Netherlands. In light of the constant inflow rates since that time and the absence of further reforms, it appears that gradual changes in the composition of applicant cohorts explain the employment decline since 2006. The higher share of vulnerable groups among applicants may point at a gradual sorting of low-skilled workers with health conditions into temporary and flexible jobs without employer obligations. This then points at changes in the underlying insured population of workers. We leave this topic for future research.

Acknowledgments: This research is sponsored by Instituut Gak. The authors are grateful to Patrick Hullegie for his indispensable work on the data. They also thank Nicole Maestas, Jan-Maarten van Sonsbeek, Eric French, Astrid Grasdal, Lawrence Katz, Marike Knoef, Carla van Deursen, Barend Barentsen and seminar participants at the Dutch Economists Day of 2019, the University of Bergen, the University of Nantes, the KVS New Paper Sessions of 2019 and the EALE/SOLE/AASLE World Meeting of 2020 for useful comments to presentations and earlier drafts of the paper. 


\section{Appendix A}

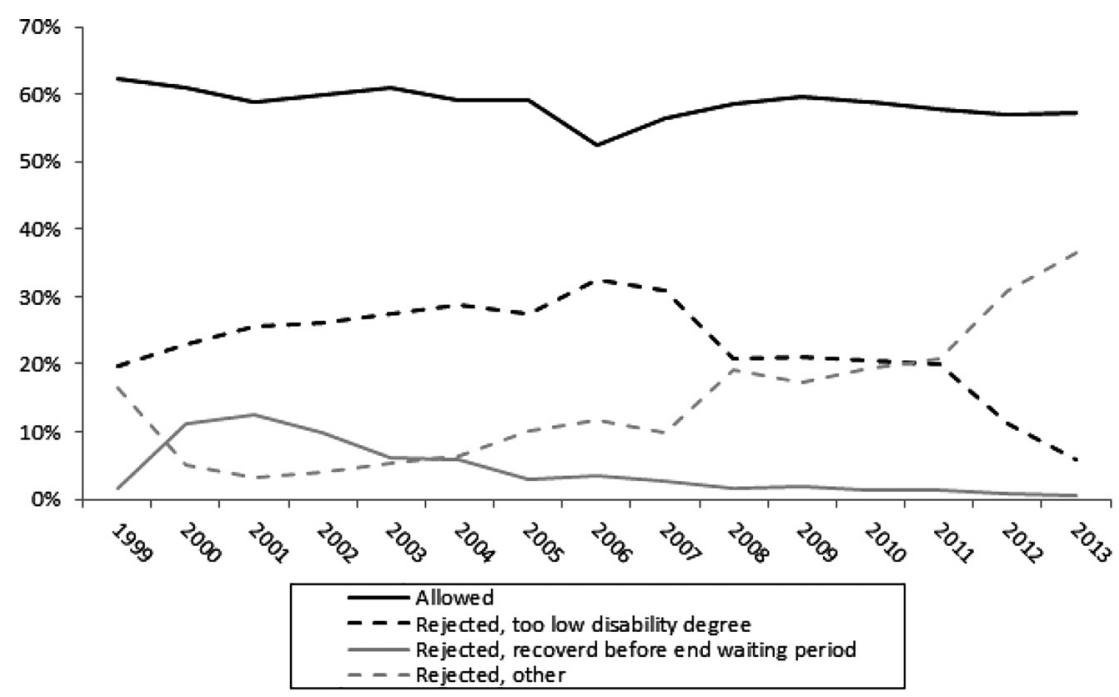

Figure A.1: Fractions of awarded and rejected DI applicants by application cohort.

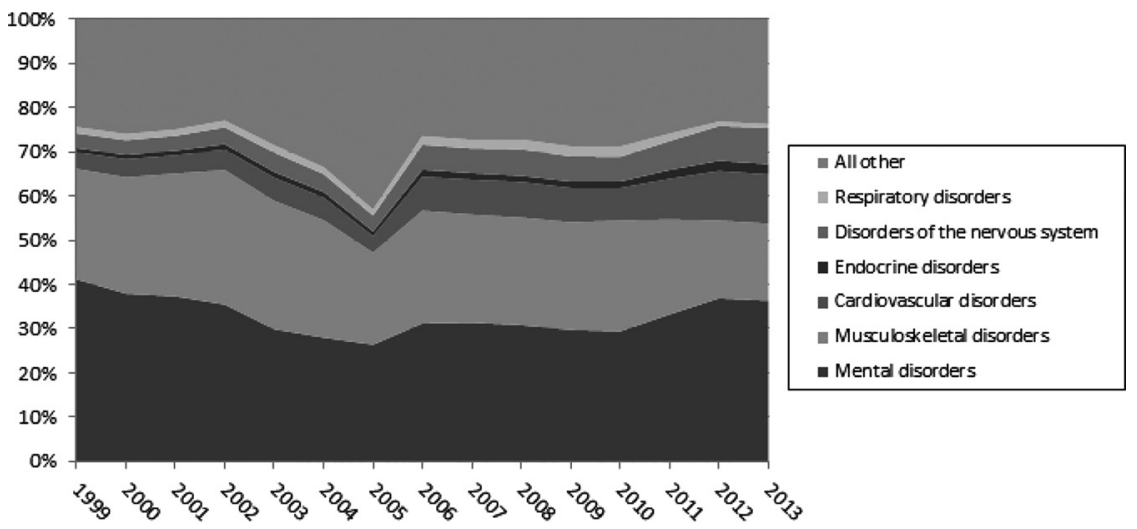

Figure A.2: Cumulative distribution of impairment groups of DI application cohorts between 1999 and 2013. 
Panel A. Positive annual earnings of rejected applicants

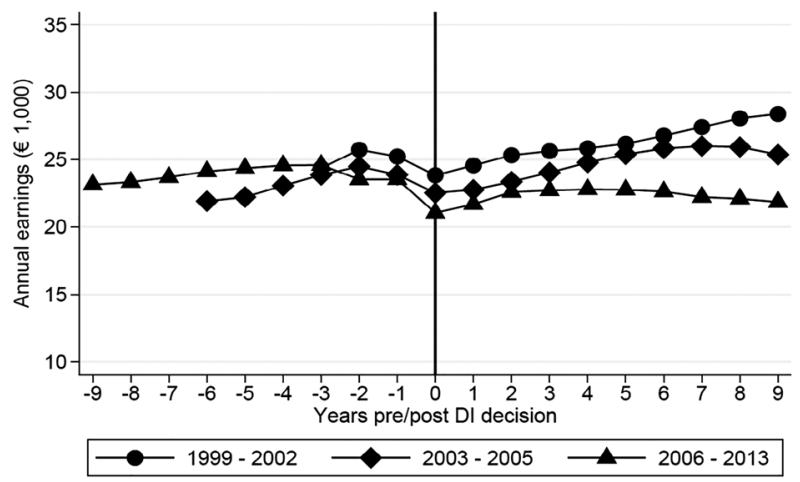

Panel B. Positive annual earnings of applicants awarded partial benefits

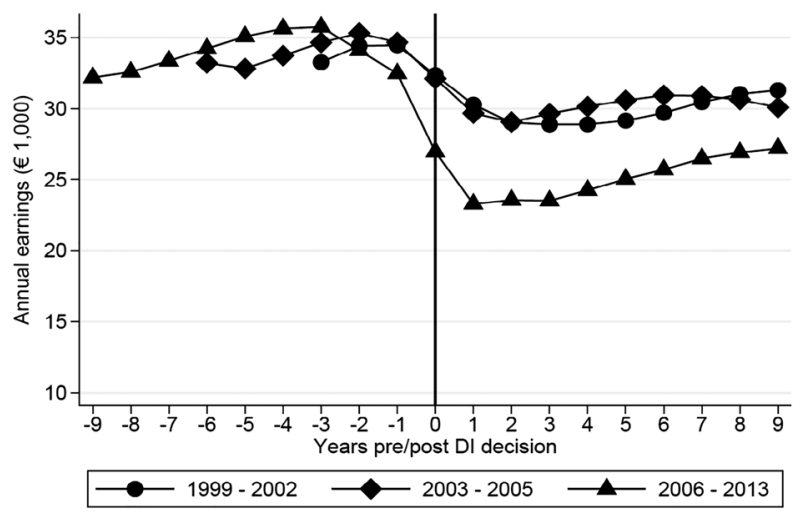

Panel C. Positive annual earnings of applicants awarded full benefits

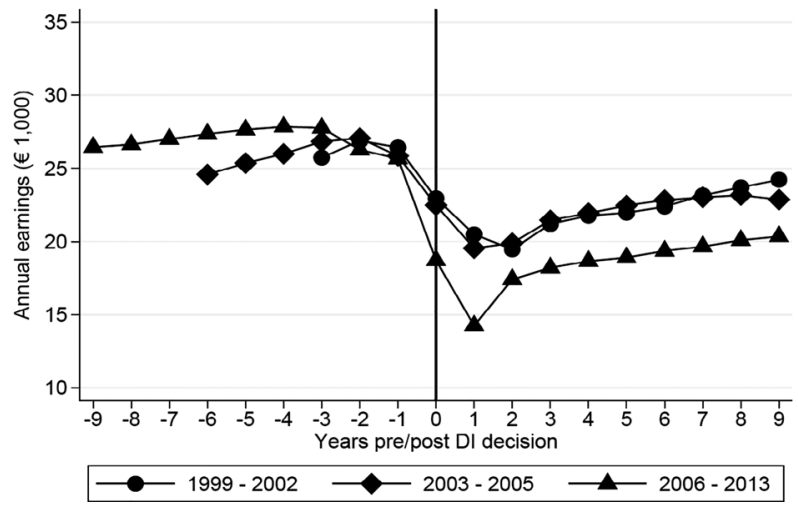

Figure A.3: Annual average earnings of rejected, and partially and fully awarded applicant cohorts for three time regimes, before and after application for DI benefits. 


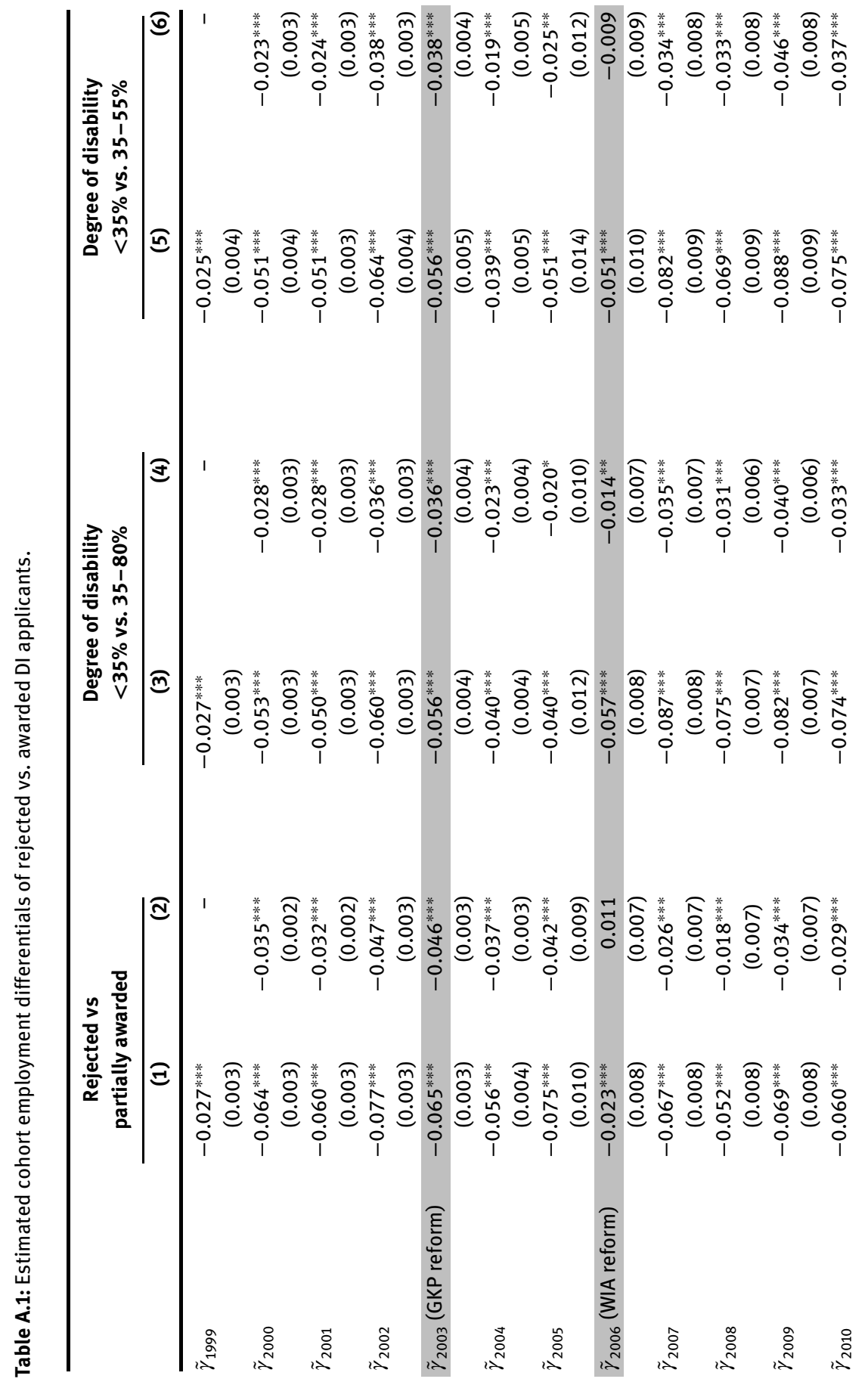




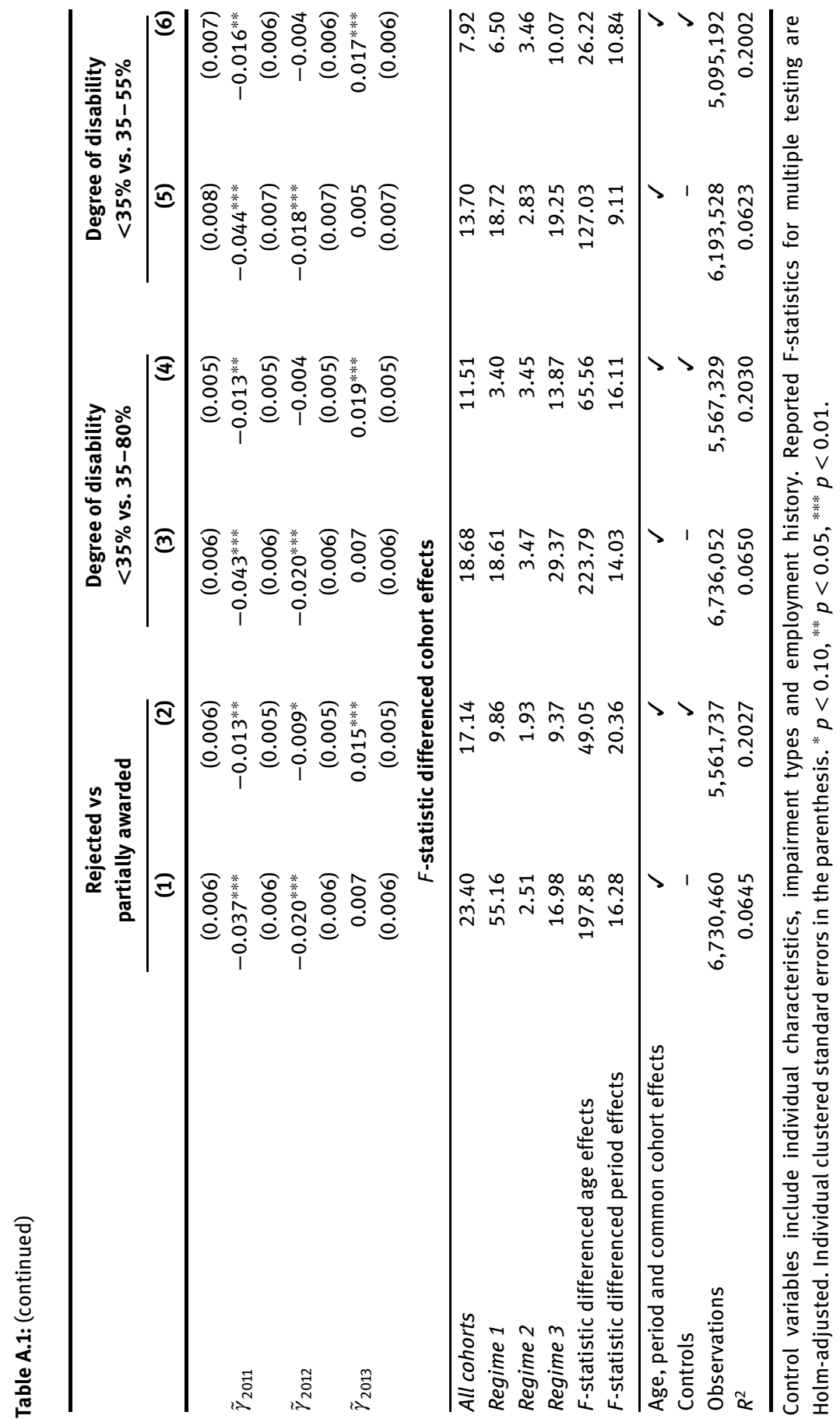


Panel A. Estimation results for rejected, and partially and fully awarded applicants

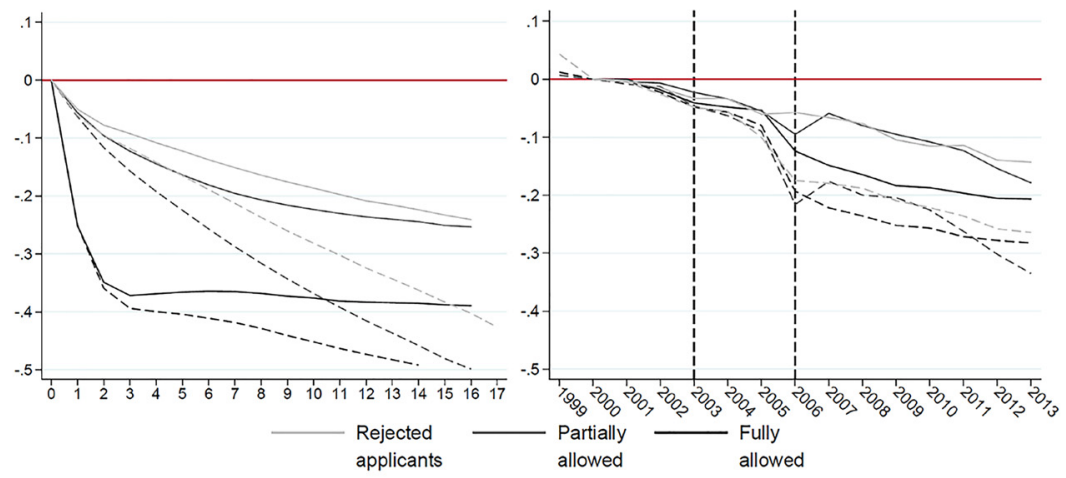

Panel B. Estimation results stratified by gender
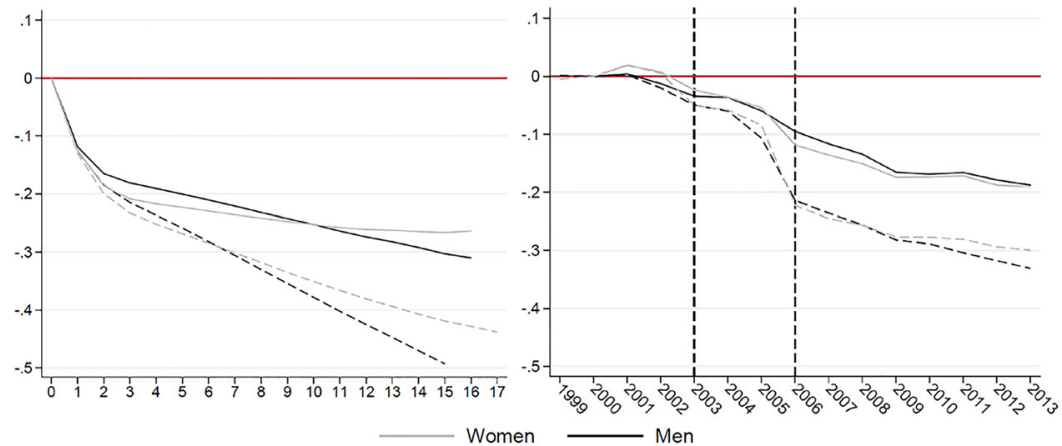

Panel C. Estimation results stratified by age at application (18-44 vs. 45-64)
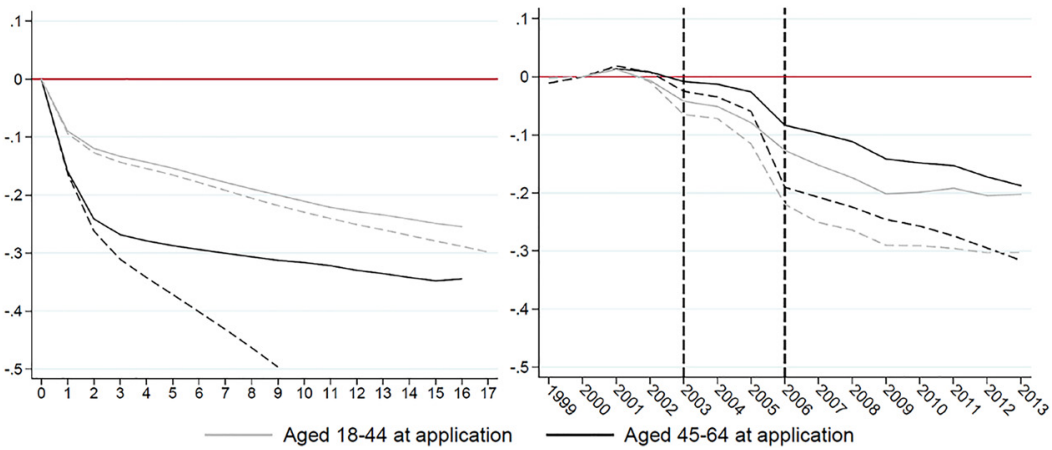

Figure A.4: Heterogeneous Deaton-Paxson employment effect estimates for age and cohort effects.

Note: Estimates without (dashed line) and with (solid line) control variables. Control variables include individual characteristics, impairment types and employment history. The sample consists of all workers who applied for DI benefits in the Netherlands between 1999 and 2013. 
Panel D. Estimation results stratified by impairment types
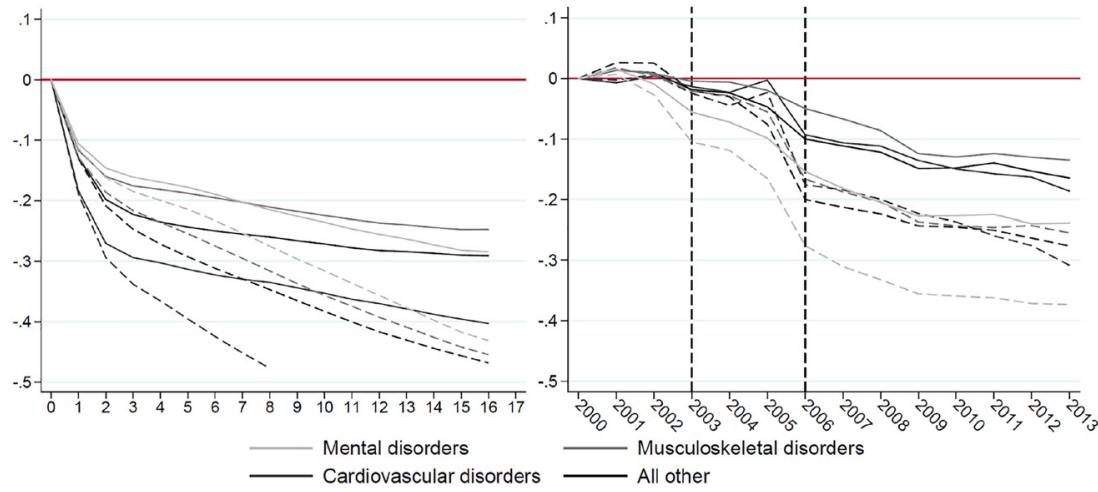

Figure A.4: (continued)

\section{Panel A. Annual gross earnings (in 2015 Euros)}
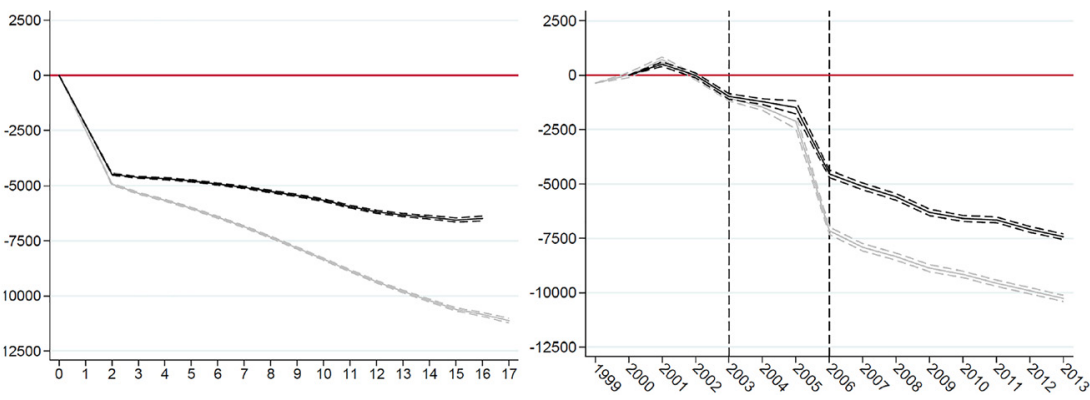

Figure A.5: Deaton-Paxson estimation results of age and cohort effects for earnings, probability of a permanent contract, $\mathrm{UI}$ benefit receipt, social assistance benefit receipt and mortality.

Note: Estimates without (grey) and with (black) control variables. Control variables include individual characteristics, impairment types and employment history. Dashed lines outline the 95-percent confidence intervals. The sample consists of all workers who applied for DI benefits in the Netherlands between 1999 and 2013. 
Panel B. Having a permanent contract
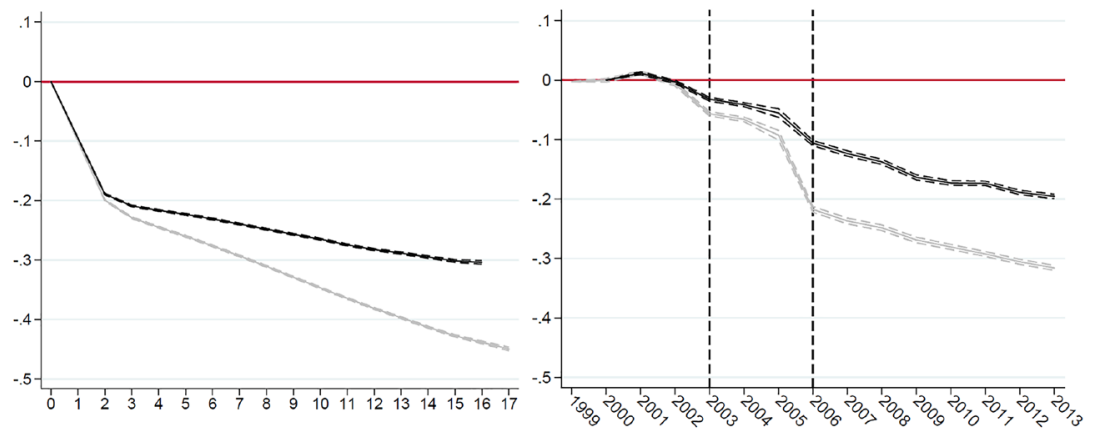

Panel C. Unemployment insurance benefit receipt
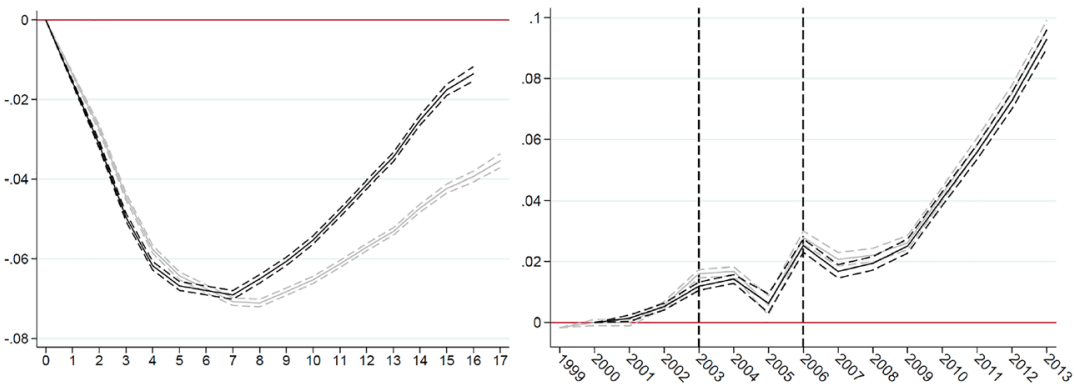

Panel D. Deceased
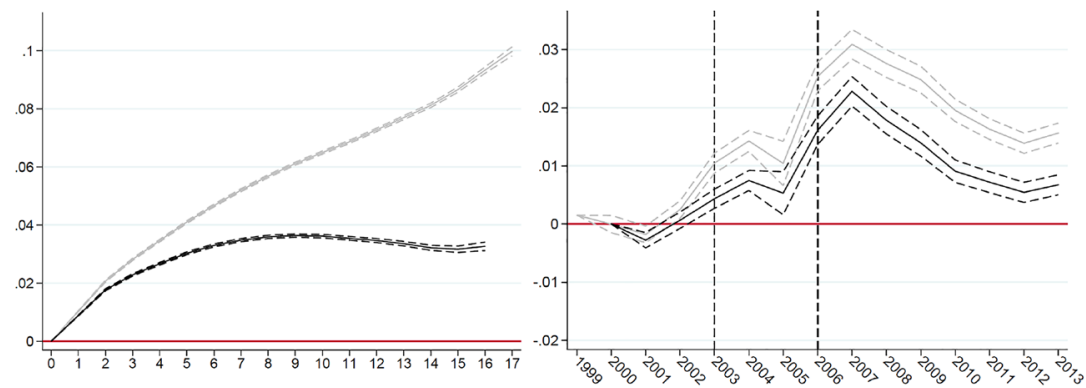

Figure A.5: (continued) 


\section{References}

Autor, D. H., and M. G. Duggan. 2003. "The Rise in the Disability Rolls and the Decline in Unemployment." Quarterly Journal of Economics 118 (1): 157-206.

Benitez-Silva, H., R. Disney, and S. Jiménez-Martín. 2010. "Disability, Capacity for Work and the Business Cycle: an International Perspective.” Economic Policy 25 (63): 483-536.

Borghans, L., A. Gielen, and E. Luttmer. 2014. "Social Support Substitution and the Earnings Rebound: Evidence from a Regression Discontinuity in Disability Insurance Reform." American Economic Journal: Economic Policy 6 (4): 34-70.

Bound, J. 1989. "The Health and Earnings of Rejected Disability Insurance Applicants." The American Economic Review 79 (3): 482.

Bound, J., R. V. Burkhauser, and A. Nichols. 2003. "Tracking the Household Income of SSDI and SSI Applicants.” In Worker Well-Being and Public Policy, 113-58. Bingley: Emerald Group Publishing Limited.

Bound, J., S. Lindner, and T. Waidmann. 2014. "Reconciling Findings on the Employment Effect of Disability Insurance." IZA Journal of Labor Policy 3 (1): 11.

Campolieti, M. 2006. "Disability Insurance Adjudication Criteria and the Incidence of Hard-To-Diagnose Medical Conditions." The B.E. Journal of Economic Analysis \& Policy 5 (1): $1-25$.

Chen, S., and W. Van der Klaauw. 2008. "The Work Disincentive Effects of the Disability Insurance Program in the 1990s." Journal of Econometrics 142 (2): 757-84.

De Groot, N., and P. Koning. 2016. "Assessing the Effects of Disability Insurance Experience Rating. The Case of The Netherlands.” Labour Economics 41: 304-17.

De Jong, P., M. Lindeboom, and B. Van der Klaauw. 2011. "Screening Disability Insurance Applications." Journal of the European Economic Association 9 (1): 106-29.

Deaton, A., and C. Paxson. 1994. "Savings, Growth and Aging in Taiwan." In Studies in the Economics of Aging, 331-62. Boston: National Bureau of Economic Research.

Deshpande, M., and Y. Li. 2019. "Who Is Screened Out? Application Costs and the Targeting of Disability Programs." American Economic Journal: Economic Policy 11 (4): 213-48.

French, E., and J. Song. 2014. "The Effect of Disability Insurance Receipt on Labor Supply." American Economic Journal: Economic Policy 6 (2): 291-337.

Godard, M., Koning, P., and Lindeboom, M. 2019. “Targeting Disability Insurance Applications with Screening." In IZA Discussion Paper 12343.

Haller, A., Staubli, S., and Zweimuller, J. 2020. "Designing Disability Insurance Reforms: Tightening Eligibility Rules or Reducing Benefits.” In NBER Working paper 27602.

Hullegie, P., and P. Koning. 2018. "Employee Health and Employer Incentives." Journal of Health Economics 62: 134-46.

Johansson, P., L. Laun, and T. Laun. 2014. "Screening Stringency in the Disability Insurance Program." The B.E. Journal of Economic Analysis \& Policy 14 (3): 873-91.

Kantarci, T., van Sonsbeek, J.-M., and Zhang, Y. 2019. "The Impact of the Disability Insurance Reform on Work Resumption and Benefit Substitution in the Netherlands." In Netspar Discussion Paper 01/2019-013.

Koning, P., and M. Lindeboom. 2015. "The Rise and Fall of Disability Insurance Enrollment in the Netherlands." The Journal of Economic Perspectives 29 (2): 151-72.

Koning, P., and J.-M. van Sonsbeek. 2017. "Making Disability Work? The Effects of Financial Incentives on Partially Disabled Workers." Labour Economics 47: 202-15. 
Koning, P., and D. J. Van Vuuren. 2010. "Disability Insurance and Unemployment Insurance as Substitute Pathways." Applied Economics 42 (5): 575-88.

Liebert, H. 2019. “Does External Medical Review Reduce Disability Insurance Inflow?” Journal of Health Economics 64: 108-28.

Maestas, N. 2019. "Identifying Work Capacity and Promoting Work: A Strategy for Modernizing the SSDI Program." The Annals of the American Academy of Political and Social Science 686 (1): $93-120$.

Maestas, N., K. J. Mullen, and A. Strand. 2013. “Does Disability Insurance Receipt Discourage Work? Using Examiner Assignment to Estimate Causal Effects of SSDI Receipt." The American Economic Review 103 (5): 1797-829.

Markussen, S., K. Røed, and R. C. Schreiner. 2018. "Can Compulsory Dialogues Nudge Sick-Listed Workers Back to Work?” The Economic Journal 128 (610): 1276-303.

OECD. 2010. Sickness, Disability and Work: Breaking the Barriers. Paris: OECD.

Van Sonsbeek, J.-M., and R. H. Gradus. 2012. "Estimating the Effects of Recent Disability Reforms in the Netherlands." Oxford Economic Papers 65 (4): 832-55.

Voas, D., and M. Chaves. 2016. "Is the United States a Counterexample to the Secularization Thesis?." American Journal of Sociology 121 (5): 1517-56.

Von Wachter, T., J. Song, and J. Manchester. 2011. "Trends in Employment and Earnings of Allowed and Rejected Applicants to the Social Security Disability Insurance Program." The American Economic Review 101 (7): 3308-29. 